\title{
Recent developments and applications of the chiral Brønsted acid catalyzed allylboration of carbonyl compounds
}

\author{
Daniel M. Sedgwick ${ }^{a, b}$ \\ Matthew N. Grayson ${ }^{c}$ \\ Santos Fustero ${ }^{\mathrm{a}, \mathrm{b}}$ \\ Pablo Barrio*a \\ a Departamento de Química Orgánica, Universidad de \\ Valencia, E-46100 Burjassot, Spain

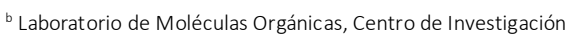 \\ Príncipe Felipe, E-46012 Valencia, Spain \\ ${ }^{c}$ Centre for Molecular Informatics, Department of Chemistry, \\ University of Cambridge, Lensfield Road, Cambridge CB2 1EW, \\ United Kingdom \\ * indicates the main/corres ponding author. \\ pablo.barrio@uv.es \\ In memory of Prof José Barluenga
}

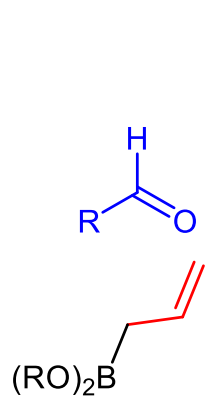

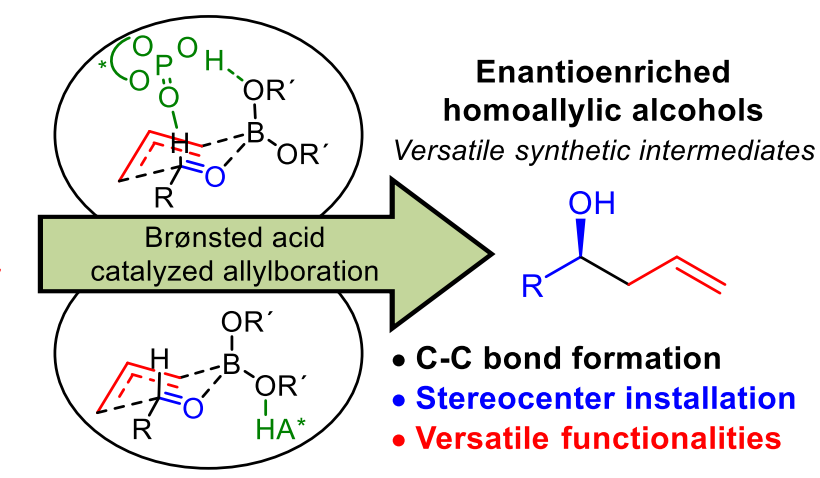

Enantioenriched

homoallylic alcohols

>

- C-C bond formation

- Versatile functionalities

\begin{abstract}
Received:
Published online:

Abstract The 50-year-old allylboration reaction has seen dramatic developments since the dawn of the new century after the first catalytic asymmetric versions came into play. In the past decade alone, several methodologies capable of achieving the desired homoallylic alcohols in over $90 \%$ e.e. have been developed. This review focuses on the chiral Brønsted acidcatalyzed allylboration reaction-covering everything from the very first examples and precedents to modern day variations and applications-and includes the following sections:

1. Introduction

2. Early developments

3. Synthetic applications

4. Variants

5. Computational contribution
\end{abstract}

Key words asymmetric synthesis, allylboration, enantioselective catalysis, chiral Brønsted acids, homoallylic alcohols, DFT calculations

\section{Introduction}

The addition of an allylmetal reagent to a carbonyl compound creates a new C-C bond, a new stereocenter and installs two versatile functionalities in close proximity of one another all in a single operation, representing a valuable transformation in synthetic organic chemistry (Figure 1 ). ${ }^{1}$

$\mathrm{M=B}, \mathrm{Si}, \mathrm{Sn}, \mathrm{Ti}, \ldots$,
$\mathrm{X}=$ alkyl, halide, alkoxide
Figure 1 Allylation of a carbonyl compound by an allylmetal species.

Although many allylmetal species have been used in such transformations, allylboron compounds stand out for a number of reasons: ${ }^{2}$ 1) allylboronates are usually bench and air-stable; 2) they can be stored for long periods without loss of activity; and
3) they can be used as chiral auxiliaries, either in the form of boranes (i.e. Brown's diisopinocampheyl) or boronic esters (i.e. Roush's dialkyltartrates). ${ }^{3}$ In addition, their reactivity can be modified by careful choice of the two remaining boron substituents. For example, Roush's tartrate derivatives readily react with aldehydes even at $-78^{\circ} \mathrm{C}$, while pinacol esters are often unreactive at room temperature. ${ }^{4}$ Such differences arise from the difference in Lewis acidity of the allylboronate-the ester groups are electron-withdrawing in character and increase the Lewis acidity of the boron compared to the pinacol derivative-which is key in their reactivity with carbonyl compounds. According to Denmark's classification, ${ }^{5}$ allylboron compounds are Type-I reagents, since the metal center is Lewis acidic enough to activate the aldehyde itself, thus creating a chair-like six-membered transition state. ${ }^{6}$ In contrast, Type-II allylating reagents, such as Sakurai's allylsilanes or Keck's allylstannanes, require the addition of an external Lewis acid to activate the aldehyde (Figure 2).

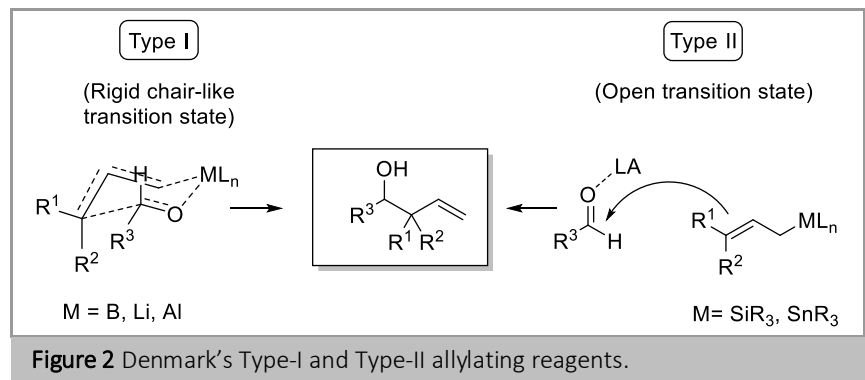

For a long time, the classification of allylboron species as Type-I reagents discouraged the development of asymmetric Lewis acid-catalyzed allylboration processes, since it was assumed that a switch from the highly ordered chair-like transition state to an open chain model was likely to occur, thus resulting in lower stereocontrol. ${ }^{7}$ Nevertheless, successful attempts at enantioselective allylboration reactions catalyzed by a chiral 
Lewis acid species were first reported at the beginning of the century. ${ }^{8}$ In 2002, Miyaura and co-workers reported that the use of catalytic amounts of the $\mathrm{Et}_{2} \mathrm{AlCl} /(S)$-BINOL complex afforded the desired homoallylic alcohols in a promising $51 \%$ ee. Furthermore, the reaction took place with complete anti diastereoselectivity for the corresponding crotyl boration, which suggested that the six-membered transition state was still operating, thereby paving the way for new enantioselective processes of this type (Scheme 1). ${ }^{8 a}$

Scheme 1 Pioneering work on the Lewis acid catalyzed enantioselective
allyboration reaction.

\section{Early developments}

2.1. $\mathrm{SnCl}_{4} /$ diol Lewis acid-assisted Brønsted acidcatalysis

The accelerating effect of a catalytic amount of a Lewis acid in the allylboration reaction of carbonyl compounds was independently disclosed by Miyaura and Hall in 2002.8a,b As suggested by Hall, later mechanistic studies showed that the activation mode does not switch the allylboron species from a Type-I to a Type-II reagent by coordination to the carbonylic oxygen. ${ }^{8 e}$ On the contrary, coordination of the Lewis acid takes place at the sterically most accessible pseudoequatorial oxygen of the boronate, in accordance with Hall (see section 5 below). This coordination results in a more electrophilic boron center which in turn enhances the electrophilicity of the carbonyl carbon in the chair-like TS (Figure 3).<smiles>[R]OB1C=CC2CC([R])(O1)O2</smiles>

Lewis acid activation by coordination to the boronate Hall (2004)

Figure 3 Pseudo-equatorial boronate oxygen Lewis acid activation.

In a following report, Hall described the first Brønsted acid catalyzed process (Scheme 2, equation a) ${ }^{9}$ thus paving the way to the chiral Brønsted acid catalyzed version implemented by the same authors one year later ${ }^{10}$ with diol-SnCl 4 complexes, using the concept of "Lewis acid-assisted Brønsted acidity", developed by Yamamoto and co-workers (Scheme 2, equation b). ${ }^{11}$ After screening a number of 1,2-diaryl-1,2-ethanediol derivatives and some of their corresponding monoethers, diol $4 \mathbf{a}$ was found to provide the highest level of enantiocontrol, while anhydrous toluene proved a slightly better solvent than dichloromethane (Scheme 2). In order to avoid the $\mathrm{SnCl}_{4}$-catalyzed non-selective background reaction, a slight excess of diol with respect to $\mathrm{SnCl}_{4}$ was required for optimum results. The authors also describe the use of a mild heterogenous inorganic base $\left(\mathrm{Na}_{2} \mathrm{CO}_{3}\right)$ as scavenger for any adventitious $\mathrm{HCl}$ that may arise from commercial $\mathrm{SnCl}_{4}$. Several representative aldehydes $\mathbf{1}$ were then subjected to these optimized reaction conditions, obtaining moderate to excellent yields and poor to good enantioselectivities (Scheme 2). Contrary to other asymmetric allylations, aliphatic aldehydes performed better than aromatic and unsaturated ones, the former ranging from $66-80 \%$ ee while the latter stay in the $10-20 \%$ ee range. The use of commercially available $(E)$ - and (Z)-crotylboronates $\mathbf{2 c , d}$ lead to lower enantioselectivities (72\% ee for the $E$ and roughly $40 \%$ for the $Z$ ) but excellent diastereoselectivities, comparable to the non-catalyzed reactions.

Scheme 2 Pioneering work on the Brønsted acid-catalyzed enantioselective

Another notable feature of this methodology is its effectiveness in diastereoselective allyl- and crotylation of chiral $\alpha$ methylaldehyde 1b, achieving 86:14 and 95:5 diastereomeric ratios respectively for the match cases (Scheme 3). The resulting propionate unit in $\mathbf{5 a}$ as well as the dipropionate triad in $\mathbf{5 c}$ are common motifs in natural products and their preparation has been a longstanding synthetic challenge. ${ }^{12}$

(R)

Scheme 3 Diastereoselective allyl-and crotylation of chiral $\alpha$-methyl aldehyde $1 b$.

In a series of publications, Hall and co-workers carried out a thorough optimization of the chiral diol skeleton seeking not only improved enantioselectivity but also a wider substrate scope with respect to both the allylating agent and the aldehyde. ${ }^{13}$ In a first attempt, the use of a BINOL-based diol (4b) was investigated (Scheme 4).13a However, the results offered no improvement and were comparable to those obtained with diol 4a. A systematic optimization of the most promising hydrobenzoin scaffold led to significant improvements after the introduction of a bulky apolar cyclooctyl ring in the ortho position (Vivol, 4c) (Scheme 4).13b This second generation ligand enabled the use of methallylboronate $\mathbf{2 e}$ in addition to the previously used allyl-and 
crotylboronates (2b-d) (Scheme 4). Furthermore, this ligand showed good enantiocontrol for a much wider substrate scope, markedly improving the enantioselectivities obtained for aromatic aldehydes (e.g. reaction with benzaldehyde resulted in $71 \%$ ee compared to $10 \%$ ee obtained with the first generation diol 4a). The improvement was especially prominent for aromatic groups bearing electron-withdrawing groups (compare $3,5-\left(\mathrm{CF}_{3}\right)_{2} \mathrm{C}_{6} \mathrm{H}_{3} \mathrm{CHO}\left(99 \%, 94 \%\right.$ ee) with 4-MeO- $\mathrm{C}_{6} \mathrm{H}_{4} \mathrm{CHO}(45 \%$, $13 \%$ ee)).

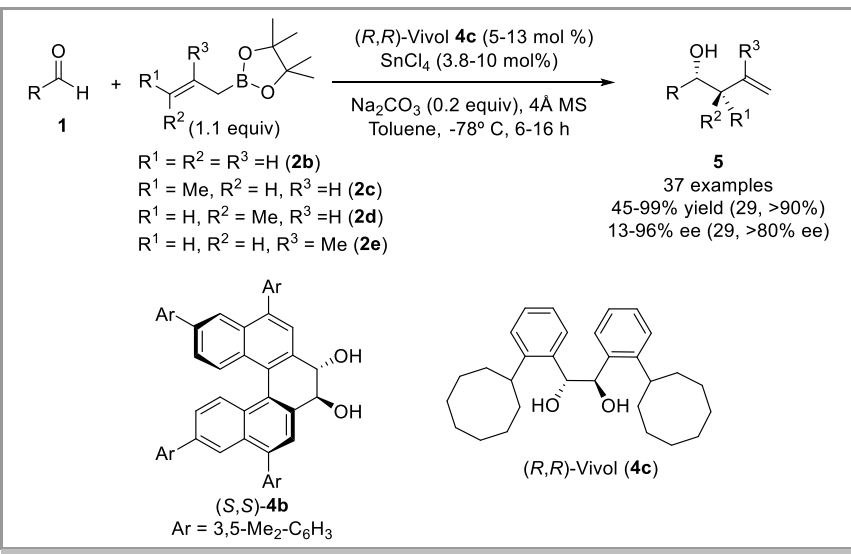

Scheme 4 Second-generation chiral diol (Vivol 4c).

The authors also carried out a thorough optimization of the reaction conditions (number of equivalents of allyl pinacolate, $\mathrm{SnCl}_{4}$ :Diol ratio, concentration) and an in-depth mechanistic study. As a result, the following conclusions were extracted: 1 ) $\mathrm{SnCl}_{4}$ is able to catalyze the reaction by itself, thus a slight excess of diol is needed (after optimization 1.3 equivalents with respect to $\mathrm{SnCl}_{4}$ was found to be optimal);2) the allyl pinacolate does not undergo in situ transesterification with the chiral diol to give a chiral allylboronic ester; and 3) a tin dialkoxide centered chiral Lewis acid is not formed, despite the presence of an inorganic base as $\mathrm{HCl}$ scavenger. Altogether, these observations endorse a Brønsted acid catalyzed process.

A small, yet significant, erosion of the enantioselectivity due to the uncatalyzed background reaction (accounting for 3-4\% of the product formation after 4-5 h) observed during the catalyst optimization prompted the authors to carry out a subsequent fine-tuning of the second generation diol Vivol (4c). The authors reasoned that a more acidic catalyst could overcome this limitation by shortening the reaction times, thereby minimizing the background reaction. To this aim, electron-withdrawing groups were introduced at the para position in order to ensure minimum disruption of the catalyst's special arrangement, key for the high levels of enantiocontrol. $p$-F-Vivol (4d) gave rise to the best results, both in terms of chemical yield and enantioselectivity, resulting in consistently improved enantiomeric excesses for all the reported examples (Scheme 5). ${ }^{13 \mathrm{c}}$

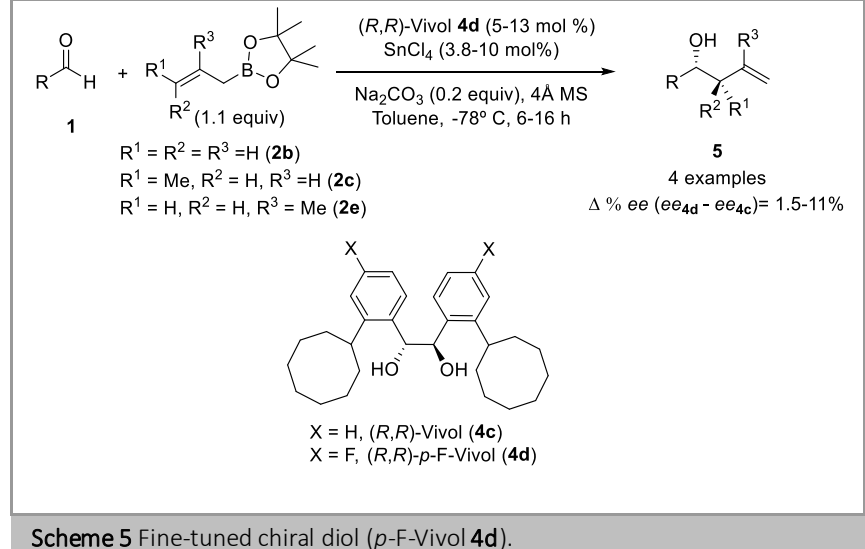

Scheme 5 Fine-tuned chiral diol ( $p$-F-Vivol $4 d$ ).

Improved Vivol derivative $4 \mathbf{d}$ was also found to catalyze the addition of 2-bromoallylboronate 2 f (Scheme 8) in high enantiomeric excess and the resulting homoallylic alcohols were used as starting materials in the synthesis of exo- $\gamma$-methylene lactones 6 (see Scheme 8 below). Moreover, the same catalyst was used in the total synthesis of the natural product dodoneine (see Scheme 9 below).

Several months after the first enantioselective allylboration report by Hall, Schaus and co-workers reported a related chiral diol-catalyzed asymmetric allylboration of ketones. ${ }^{14}$ There are, however, major differences between this and Hall's work: 1) ketones rather than aldehydes are used as substrates; and 2) the catalyst is a BINOL-derived diol without the assistance of a Lewis acid. A Brønsted acid catalyzed mechanism was claimed by the authors based on mechanistic studies; however, subsequent computational studies by Goodman and Pellegrinet supported a Lewis acid catalyzed pathway instead. ${ }^{15}$ Therefore, we have decided not to cover these reports in detail here.

\subsection{Chiral BINOL-phosphoric acid-catalysis}

Since their advent in 2004,16 chiral BINOL-derived phosphoric acid catalysts have found increasing applicability in asymmetric synthesis. ${ }^{17}$ In 2010, combining Hall's observations with the versatility of chiral phosphoric acids, Antilla described the use of such catalysts for the enantioselective allylboration of aldehydes (Scheme 6). ${ }^{18,19}$ Complementary to Hall's catalytic system, the use of $(R)$-TRIP 7a resulted in the highest enantioselectivities for aromatic and alkenyl aldehydes 1 (14 examples, 91-99\% yield, 91-99\% ee). The reaction conditions were also found to be effective in the corresponding crotylboration process, resulting in excellent yields, diastereo- and enantioselectivities. In this preliminary communication, the authors assume an activation mode consisting of the protonation of the pseudo-equatorial oxygen of the cyclic boronate, in agreement with previous studies by Hall (Scheme 6) (for a thorough discussion on the mechanistic details of this transformation, see section 5 below). The commercial availability of several BINOL-derived phosphoric acids has resulted in several synthetic applications of this methodology as well as in a number of variants (see next sections). 


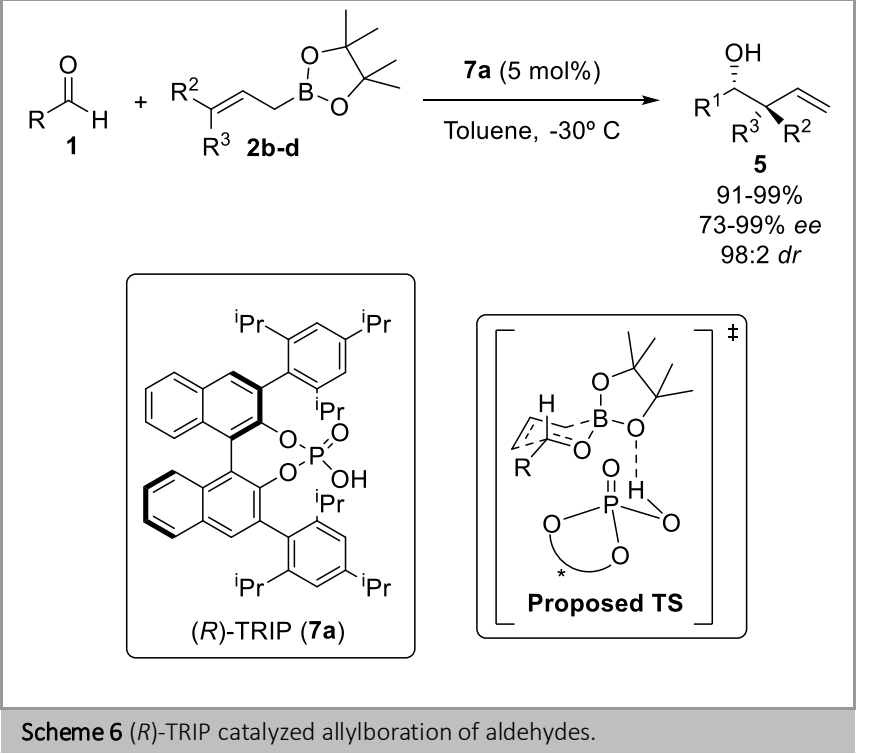

Two years later, $\mathrm{Hu}$ and co-workers reported improved enantioselectivities in the allylboration of aldehydes by using a phosphoric acid based on a different chiral scaffold: SPINOL $\mathbf{7 b} \mathbf{b}^{20}$, ${ }^{21}$ This improved selectivity was significant in the case of aliphatic aldehydes ( $\Delta \%$ ee up to $18 \%$, for $\mathrm{R}=\mathrm{Cy}$ ) (Scheme 7). The reaction conditions are very similar to those reported by Antilla when using $(R)$-TRIP as the catalyst, except when Hu carried out the reactions at a lower temperature $\left(-70\right.$ vs $\left.-30^{\circ} \mathrm{C}\right)$. Interestingly, the highest enantioselectivity arose when the same 2,4,6triisopropylphenyl substituents were flanking the phosphoric acid (Scheme 7).

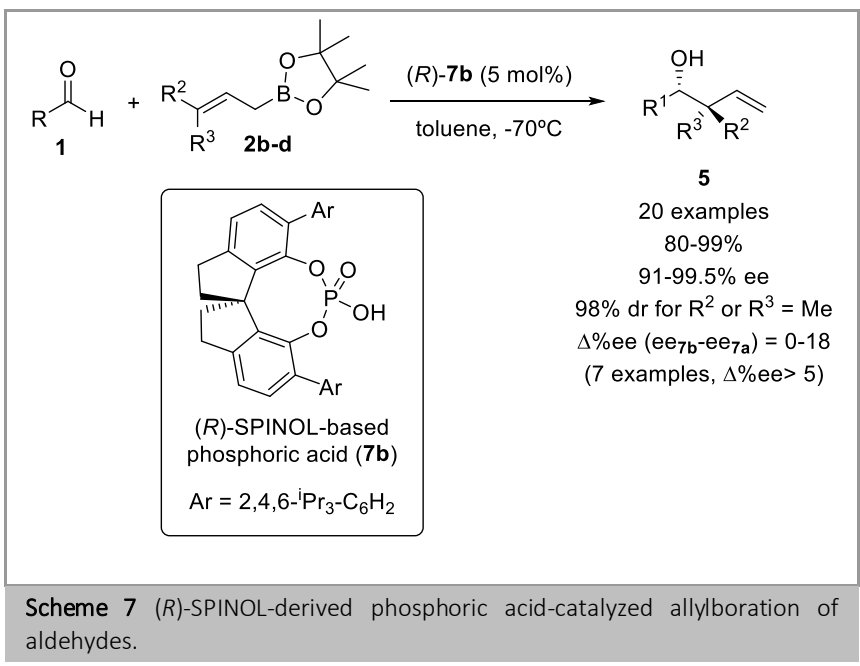

\section{Synthetic applications}

As previously mentioned, Hall applied his $p$-F-Vivol catalyst (4d) to allylboration reactions using 2-bromoallylboronate (2f) to obtain synthetic intermediates $\mathbf{8}$ well-suited for the preparation of enantioenriched $\alpha$-exo-methylene- $\gamma$-lactones (6) by means of nickel-promoted carbonylative cyclization (Scheme 8). ${ }^{13 c}$

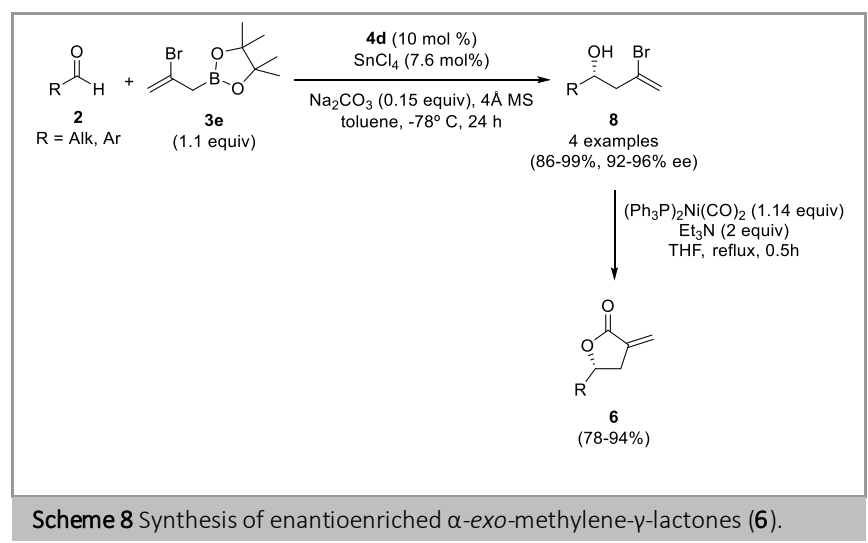

Moreover, the same catalyst was used in the total synthesis of $(+)$ dodoneine 9 (Scheme 9), ${ }^{13 c, 22,23}$ a naturally occurring $\delta$-lactone isolated from a parasitic plant in Burkina Faso. ${ }^{24}$ Two $(R, R)-p$-FVivol.SnCl $\mathrm{Sn}_{4}$-catalyzed allylation reactions were used in order to access the syn 1,3-diol subunit present in the natural product, one of which is embedded in a lactone core. In order to allow for comparison of their methodology with previous ones, the synthetic route was analogous to that described by Marco and Cossy. ${ }^{23}$ The synthesis began with the $(R, R)-p$-F-Vivol-SnCl ${ }_{4}$ catalyzed allylboration of silyloxy aldehyde 11, prepared from dihydro-p-coumaric acid 10,23a affording homoallylic alcohol 12 in $99 \%$ yield and $97 \%$ enantiomeric excess (Scheme 9). This result showcased the efficiency of the newly developed catalytic system in the allylboration of aliphatic aldehydes, improving on the $90 \%$ ee obtained when using Brown's allylation ${ }^{23 a}$ and the $95 \%$ ee obtained in the asymmetric Keck reaction, ${ }^{25}$ which also proceeded in a much lower chemical yield. Protection of alcohol 12 with TBSOTf, followed by ozonolysis of the double bond afforded aldehyde 13, the substrate for the second enantioselective allylboration reaction (Scheme 9). Again, the resulting homoallylic alcohol $\mathbf{1 4}$ was obtained in excellent yield and with almost complete stereocontrol (96\%, 99:1 dr); similar to the diastereoselectivity reported for Brown's allylboration, but in much higher chemical yield (Scheme 9). ${ }^{23 a}$ The last steps of the synthesis included esterification of the free alcohol with acryloyl chloride, ring closing metathesis and deprotection of the hydroxyl functionalities, similar to Marco's synthesis (Scheme 9).

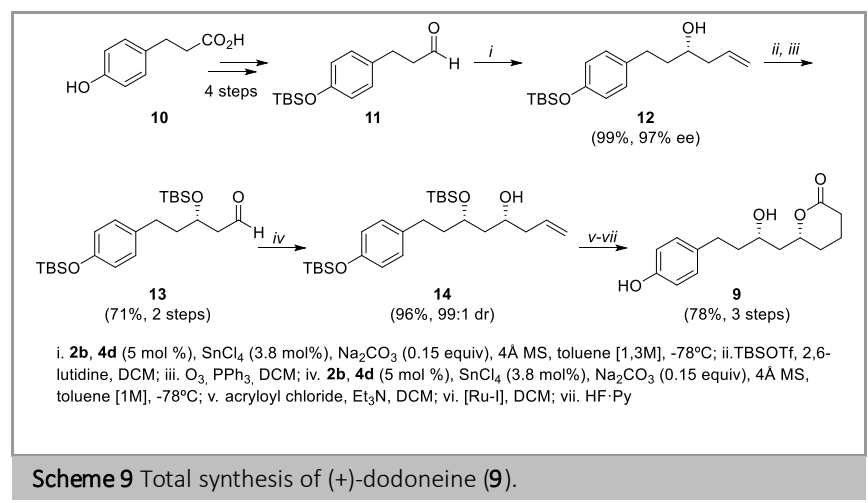

Soon after, a similar approach was published by Allais and Ducrot (Scheme 10). ${ }^{22}$ Intermediate $\mathbf{1 2}$ was achieved using Hall's conditions (see above). From 12, the main differences with the aforementioned methodology are: 1) the second allylation step is performed taking advantage of the inherent diastereoselectivity imposed by the previously installed stereocenter (instead of 
using a second $\mathbf{4 d} \cdot \mathrm{SnCl}_{4}$-catalyzed reaction); and 2) the lactone ring is constructed by means of a $Z$-selective HornerWadsworth-Emmons olefination using Still-Gennari fluorinated phosphonoacetate $\mathbf{1 6}$ (Scheme 10).

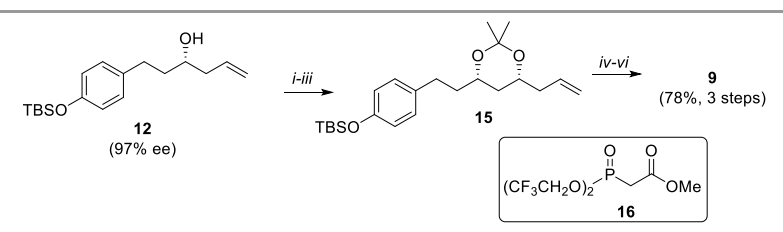

i. $\mathrm{OsO}_{4}, \mathrm{NalO}_{4}$ 2,6-lutidine, dioxane/ $\mathrm{H}_{2} \mathrm{O}$; ii.allylTMS, $\mathrm{SnCl}_{4} \mathrm{DCM},-78^{\circ} \mathrm{C}$; iii.PPTS, DCM, rt; iv. $\mathrm{OsO}_{4}$ $\mathrm{NalO}_{4}$, 2,6-lutidine, dioxane $/ \mathrm{H}_{2} \mathrm{O}$; v. $16,18-\mathrm{C}-6, \mathrm{THF},-78^{\circ} \mathrm{C}$; vi. $80 \% \mathrm{AcOH}_{\text {aq }}, 60^{\circ} \mathrm{C}, 1 \mathrm{~d}$.

Scheme 10 Total synthesis of (+)-dodoneine (9) by Allais and Ducrot.

In a continuing effort to showcase the applicability of their methodology, in 2009 Hall also reported the use of their $p$-F-Vivol catalyst (4d), along with other boron-based methodologies, in the total synthesis of the most complex natural product ever made using a Brønsted acid-catalyzed enantioselective allylboration as a key step, palmerolide A (17) (Scheme 11). ${ }^{13 \mathrm{~d}}$ More specifically, the enantioselective allylation step was used in the synthesis of the left fragment 18 (Scheme 11).

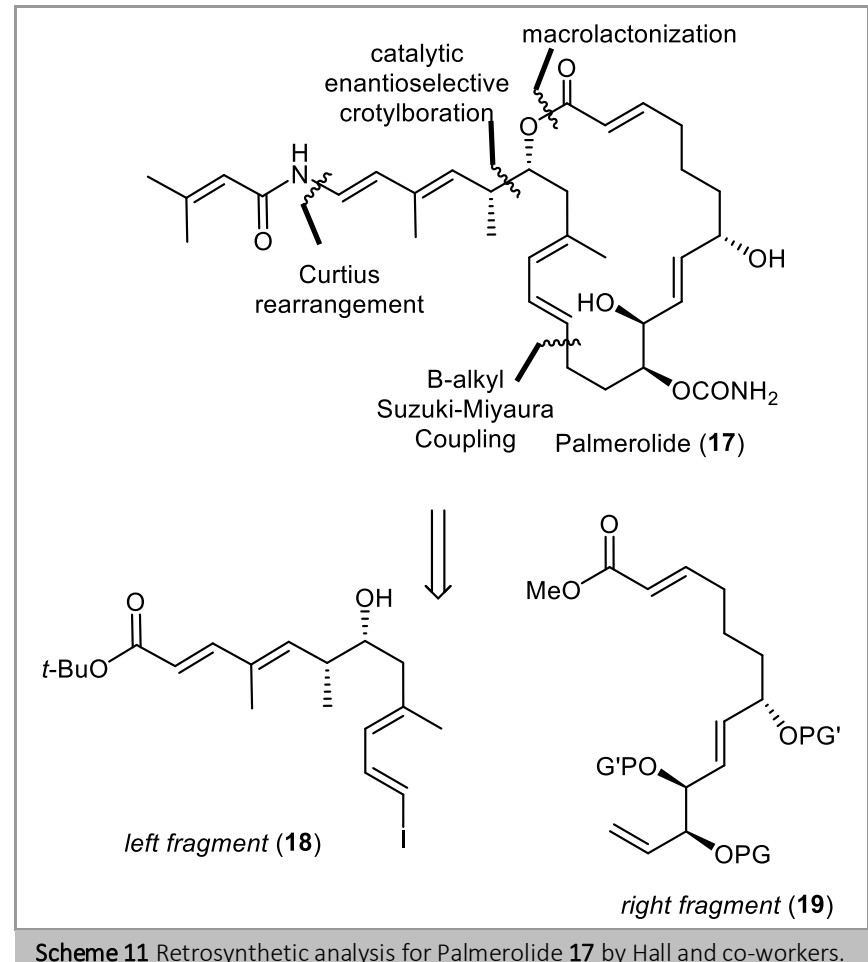

The construction of $\mathbf{1 8}$ began with the key catalytic enantioselective $E$-crotylboration of aldehyde $\mathbf{2 0}$ using the $p$-FVivol catalyst (4d) (Scheme 12). The right configuration at the C19 hydroxyl group was achieved with concomitant protection, followed by several conventional synthetic transformations, namely oxidative cleavage of the terminal alkene and Wittig olefination affording intermediate $\mathbf{2 2}$ in acceptable overall yield (Scheme 12). Extension of the unsaturated ester followed by the installation of the iododiene scaffold, by means of a Sonogashira coupling/alkyne hydrozirconation reaction sequence, afforded left fragment 18 (Scheme 12).

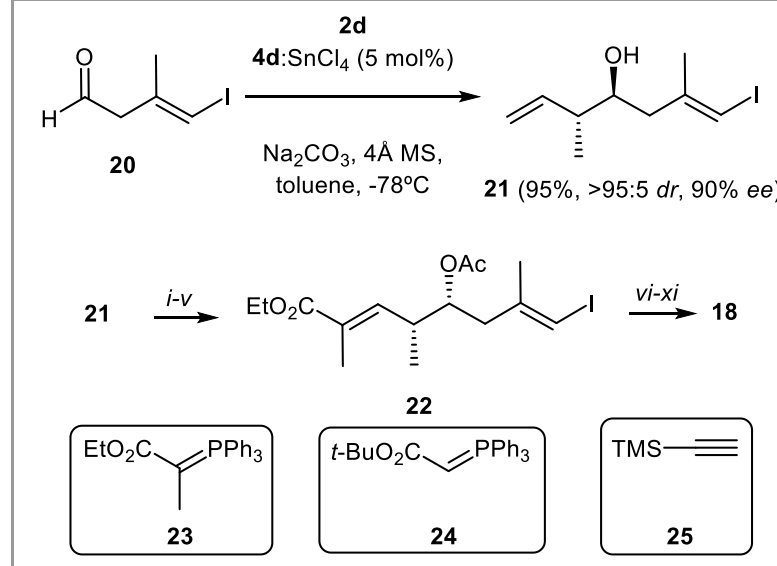

i. $\mathrm{MsCl}, \mathrm{Et}_{3} \mathrm{~N}, \mathrm{DCM},{ }^{\circ} \mathrm{C}$; ii. CsOAc, 18-C-6, toluene, reflux; iii. $\mathrm{OsO}_{4}, \mathrm{NMO}$, $t$-BuOH/ $\mathrm{H}_{2} \mathrm{O} / \mathrm{THF}$; iv. $\mathrm{NalO}_{4}, \mathrm{MeOH} / \mathrm{H}_{2} \mathrm{O}$; v. 23, DCM, rt; vi. DIBAL-H, $\mathrm{DCM},-78{ }^{\circ} \mathrm{C}$; vii. $\mathrm{MnO}_{2} \mathrm{DCM}$, rt; viii. 24, benzene, reflux; ix. 25, $\left(\mathrm{Ph}_{3} \mathrm{P}\right)_{2} \mathrm{PdCl}_{2}$ Cul, Et $\mathrm{NHH}_{2}$ x. TBAF, THF, rt; xi. $\mathrm{Cp} \mathrm{p}_{2} \mathrm{Zr}(\mathrm{H}) \mathrm{Cl}, \mathrm{I}_{2}$ THF

Scheme 12 Synthesis of left fragment 18 using p-F-Vivol-catalyzed enantioselective $E$-crotylboration as the key step.

The synthesis of the right fragment and the final steps towards the construction of the natural product do not include any chiral Brønsted acid-catalyzed allylboration step and, therefore, are beyond the scope of this review.

In 2014, Hall reported the application of the $(R, R)-p$-F-Vivol-SnCl 4 catalytic system to the asymmetric allylboration of propargyl aldehydes $\mathbf{2 6}$ (Scheme 13). ${ }^{26}$ The main modification with respect to the use of other aldehydes as substrates was the use of the allylboronate derived from 2,2-dimethyl-1,3-propanodiol $\mathbf{2 g}$ instead of the usual pinacolate, as the optimum allylating reagent (Scheme 13). The reaction is similar to that reported by $\mathrm{Hu}$ in 2012 using SPINOL-derived phosphoric acids which contained several examples with propargyl aldehydes. ${ }^{20}$ However, the authors were able to showcase the synthetic utility of the resulting enynols $\mathbf{2 7}$ by using the corresponding propargyl acetates in gold catalysis (Scheme 13).

$$
\text { Scheme } 13 \text { Use of propargyl aldehydes } 26 \text { as substrates. }
$$

In 2013, Barrio and Fustero envisioned the possible application of the reaction conditions developed by Antilla to a catalytic process consisting of an asymmetric allylboration/RCM sequence using aldehydes bearing a pendant double bond in an appropriate position 29 (Scheme 11).27,28 The compatibility of BINOL-phosphoric acids with transition metals in binary catalytic systems, and more specifically with ruthenium-based olefin metathesis catalysts, was already well-established.29,30 The authors took advantage of the lack of reactivity of the metathesis catalyst at low temperatures in order to carry out the asymmetric 
allylboration in the presence of this latent species, whose reactivity would then be triggered by allowing the reaction to warm to room temperature, thereby avoiding an undesired cross-metathesis event prior to allylboration. A wide variety of products $\mathbf{3 0}$ were obtained in good to excellent yields, including benzo- and heteroaryl-fused six- and seven-membered rings. Two aliphatic examples were also reported, albeit with somewhat diminished enantioselectivities (67 and 84\% ee, respectively).

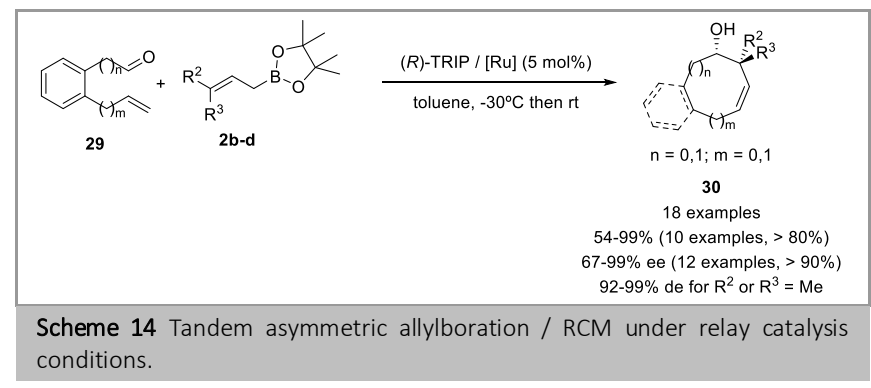

In a following report, the same authors reported the use of orthoalkynyl benzaldehydes $\mathbf{3 1}$ as privileged scaffolds for DiversityOriented Synthesis (DOS). ${ }^{31,32}$ More specifically, the enynes 32 obtained upon asymmetric allylboration were engaged in several synthetically relevant transformations: the ring-closing enyne metathesis (RCEYM) (33); the intramolecular Pauson-Khand reaction (34); and the gold-catalyzed intramolecular hydroalkoxylation (35), thus generating molecular complexity and diversity rapidly (Scheme 15). The authors observed a marked dependence of the enantioselectivity on the substitutions at the triple bond; ${ }^{33}$ high levels of enantiocontrol were only achieved for aryl substituted substrates (Scheme 15). This experimental observation was then studied theoretically and the factors governing enantioselectivity were revealed (see section 5 below). The enantioselectivities obtained in the related propargylboration reaction followed a similar trend with regards to the substitution at the triple bond.

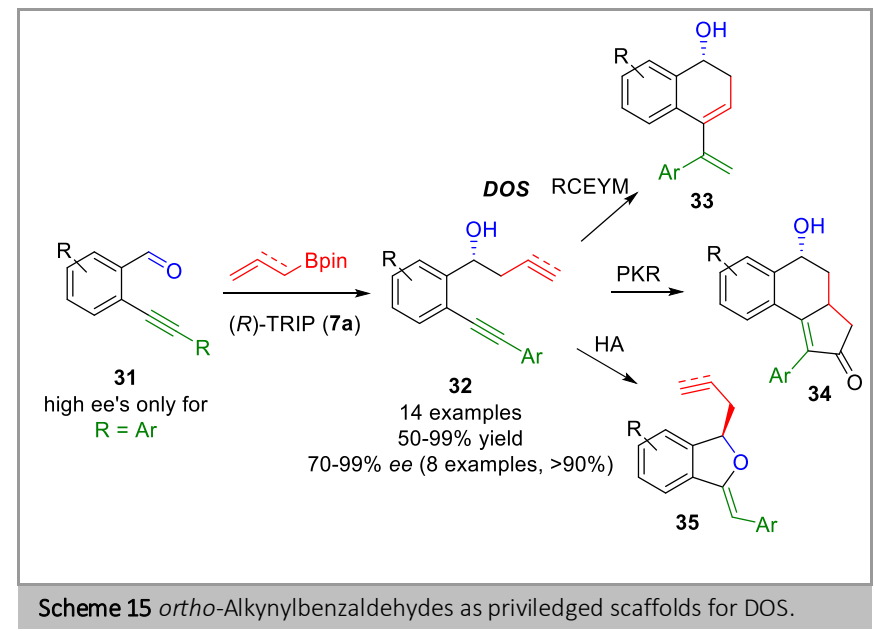

In addition to the use of substituted aldehydes to access densely functionalized intermediates, Barrio also explored the complementary approach in collaboration with Akiyama, that is, the use of functionalized allylboronate derivatives (Scheme 16).

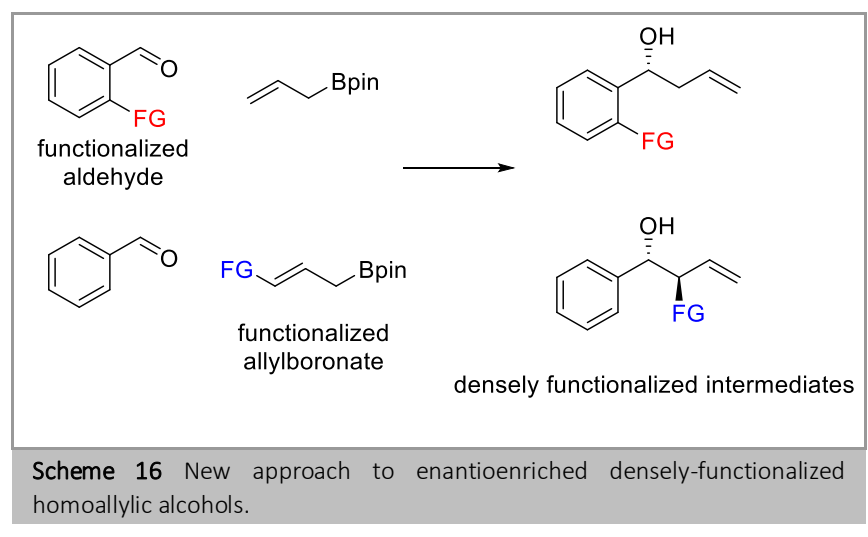

In 2015 , they reported the use of a $\gamma$-silylallylboronate $\mathbf{2} \mathbf{i}$ for the first time in enantioselective catalysis. ${ }^{34,35}$ This approach generates enantioenriched $\alpha$-silylhomoallylic alcohols 36 amenable to further transformations. The authors subjected these compounds to Gouverneur's conditions for electrophilic fluorination $^{36}$ affording $\gamma$-fluoroallylic alcohols 37: unprecedented building blocks and interesting compounds given the prevalence of fluorine in modern organic chemistry (Scheme 17). ${ }^{37}$ The use of this bulkier allylboronate derivative required a new optimization of the reaction conditions. In this case, 9anthryl BINOL phosphoric acid derivative $7 c$ resulted in the highest enantioselectivity (Scheme 17). The more robust $\mathrm{PhMe}_{2} \mathrm{Si}$-substituted products could also be obtained, however another catalyst (the corresponding $\mathrm{H}_{8}$-derivative) was required in order to obtain high levels of enantioselectivity ( 2 examples, $87 \%$ ee).

Scheme 17 New approach to enantioenriched densely-functionalized

In a series of reports, Kotora applied Antilla's TRIP-catalyzed asymmetric allylboration of aldehydes to the synthesis of several biorelevant compounds such as a Flobufen metabolite $\mathbf{3 8}$ and dapoxetine $39^{38}$ or the natural products (+)-pteroenone $40^{39}$ and coibacin D $\mathbf{4 1}^{40}$ (Schemes 18-21). The synthesis of 38, a metabolite of the antiinflamatory agent Flobufen, ${ }^{41}$ starts with the asymmetric allylboration of the known aldehyde 42, affording homoallylic alcohol 43 in 98\% yield and 99\% ee (Scheme 15). ${ }^{38}$ The Brønsted acid catalyzed procedure proved superior, in this case, to the Lewis base catalyzed variant using allyltrichlorosilane and axially chiral $N$-oxides, previously used successfully by the same authors. ${ }^{42}$ A sequence of conventional transformations, including protection/deprotection steps, double bond hydroboration/oxidation, lactonization and enolate alkylation then rendered the desired product 38 (Scheme 18). 


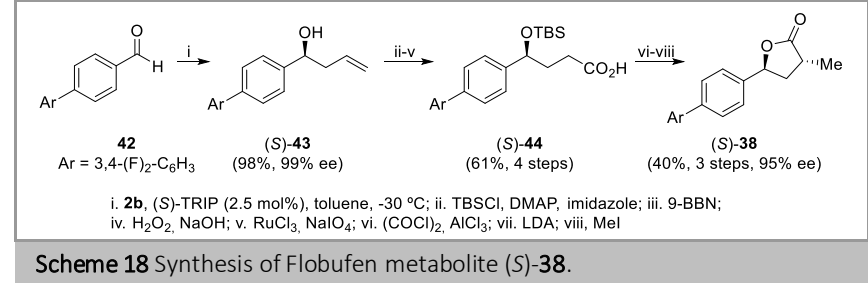

Similarly, the synthesis of dapoxetine $\mathbf{3 9}^{43}$-a serotonin transport inhibitor (comercialized as Priligy) and the first compound developed for the treatment of premature ejaculation-began with the TRIP-catalyzed asymmetric allylation of benzaldehyde 1a, that took place in excellent yield and enantioselectivity (Scheme 19). The key stereoretentive transformation of the alcohol $\mathbf{4 5}$ into the corresponding amine was carried out in two steps following the elegant methodology reported by Jung based on the use of chlorosulfonyl isocyanate (CSI, 46) ${ }^{44}$ in good overall yield but with a significant loss of optical purity, affording Cbz-protected amine 47 (Scheme 19). The synthesis was completed by means of oxidative cleavage of the homoallylic double bond followed by reduction of the corresponding aldehyde, amine deprotection, Eschweiler-Clarke methylation and ether formation via a Mitsunobu reaction with 1-naphthol (Scheme 19). The final steps proceeded with moderate to good yields, and unfortunately a significant loss of optical purity was again observed along the synthetic sequence; however, the product was still obtained in a synthetically satisfactory $85 \%$ ee (Scheme 19).

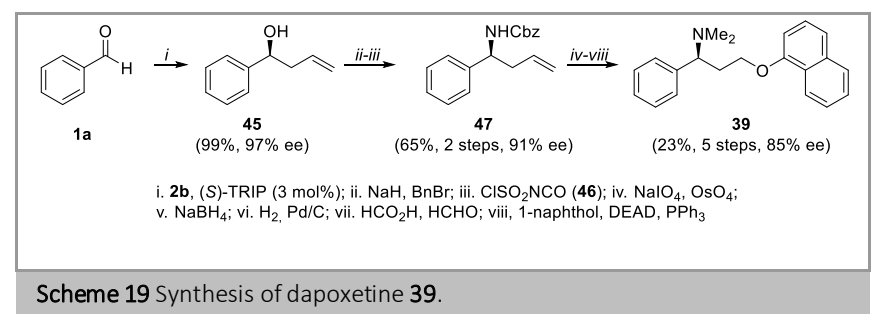

In a subsequent report, Kotora describes the TRIP-catalyzed asymmetric allyl- and crotylboration of (2E,4E)-2,4dimethylhexadienal $\mathbf{4 8}$ and its application to the total synthesis of the natural product $(5 R, 6 S)-(+)$-pteroenone $\mathbf{4 0 . 4 5}$ Again, the authors compared Antilla's TRIP-catalyzed methodology with a range of other catalytic enantioselective methods: Yamamoto's AgOTf/BINAP/KF/18-crown-6 catalyzed allylation with allyltrimethoxysilane (2j); ${ }^{\text {;a }}$ asymmetric Keck allylation using a stoichiometric amount of Ti(Oi-Pr) 4 /BINOL (1,1'-bi-2-naphthol) and allyltributylstannane $(\mathbf{2 k}) ;^{7 \mathrm{c}}$ the aforementioned chiral $\mathrm{N}$ oxide-catalyzed addition of allyltrichlorosilane (2l); ${ }^{42}$ and Brown's isopinocampheyl borane $(\mathbf{2 m})$ allylation $^{3 \mathrm{a}, \mathrm{b}}$ were all tested (Table 1, Entries 1-5). ${ }^{39}$ Again, the TRIP-catalyzed allylation proved superior to all of these methods both in terms of chemical yield and enantioselectivity. However, the chiral $\mathrm{N}$ oxide-catalyzed crotylations using the corresponding $(E)$ - and $(Z)$-crotyltrichlorosilanes (2n,o) proved to be strong competitors giving rise to comparable-and in some cases superior-yields, enantio-, and diastereoselectivities (Table 1, Entries 6-9).
Table 1 Comparison of several methodologies for the asymmetric allyl- and crotylboration of $(2 E, 4 E)$-2,4-dimethylhexadienal 48 .

\begin{tabular}{|c|c|c|c|c|c|}
\hline & ${ }_{48}$ & $\begin{array}{l}+\mathrm{R}^{1} \\
{[\mathrm{M}]=\mathrm{Bpin}, \mathrm{R}^{1}=\mathrm{R}^{2}=\mathrm{H}, \mathbf{2}} \\
{[\mathrm{M}]=\mathrm{Bpin}, \mathrm{R}^{1}=\mathrm{Me}, \mathrm{R}^{2}=} \\
{[\mathrm{M}]=\mathrm{Bpin}, \mathrm{R}^{1}=\mathrm{H}, \mathrm{R}^{2}=\mathrm{M}} \\
{[\mathrm{M}]=\mathrm{Si}(\mathrm{OMe})_{3}, \mathrm{R}^{1}=\mathrm{R}^{2}=} \\
{[\mathrm{M}]=\mathrm{SnBu}_{3}, \mathrm{R}^{1}=\mathrm{R}^{2}=\mathrm{H},} \\
{[\mathrm{M}]=\mathrm{SiCl}_{3}, \mathrm{R}^{1}=\mathrm{R}^{2}=\mathrm{H}, \mathbf{2}} \\
{[\mathrm{M}]=\mathrm{B}(\mathrm{Ipc})_{2}, \mathrm{R}^{1}=\mathrm{R}^{2}=\mathrm{H},} \\
{[\mathrm{M}]=\mathrm{SiCl}_{3}, \mathrm{R}^{1}=\mathrm{Me}, \mathrm{R}^{2}=} \\
{[\mathrm{M}]=\mathrm{SiCl}_{3}, \mathrm{R}^{1}=\mathrm{H}, \mathrm{R}^{2}=\mathrm{M}}\end{array}$ & tions & ${ }_{\mathrm{Ph}}^{\mathrm{a}-\text {-dioxide }}$ & \\
\hline Entry & 2 & Catalyst (mol\%) & Yield (\%) & ee $(\%)$ & $d r$ \\
\hline 1 & $2 j$ & (S)-BINAP/AgOTf/KF (5) & 27 & 77 & - \\
\hline 2 & $2 k$ & (S)-BINAP/AgOTf (30) & 40 & 89 & - \\
\hline 3 & $2 b$ & (S)-TRIP-PA (15) & 90 & 85 & - \\
\hline 4 & 21 & $\left(R, S_{a}\right)$-dioxide $(5)$ & 57 & 69 & - \\
\hline 5 & $2 m$ & - & 67 & 63 & - \\
\hline 6 & $2 c$ & (S)-TRIP-PA (10) & 64 & 93 & $>30: 1$ \\
\hline 7 & $2 n$ & $\left(R, S_{a}\right)$-dioxide & 68 & 96 & $19: 1$ \\
\hline 8 & $2 d$ & (S)-TRIP-PA (10) & 64 & 80 & $1: 19$ \\
\hline 9 & 20 & $\left(R, S_{a}\right)$-dioxide & 49 & 85 & $1: 30<$ \\
\hline
\end{tabular}

Finally, the TRIP-catalyzed anti-crotylation was chosen as the key step for the total synthesis of $(5 R, 6 S)-(+)$-pteroenone 40 obtaining homoallylic alcohol 49a in improved yield and enantioselectivity by carrying out the reaction at $-30{ }^{\circ} \mathrm{C}$ (Scheme 20). TBS protection of the secondary alcohol followed by Wacker oxidation of the terminal double bond afforded protected $\beta$ hydroxyketone $\mathbf{5 0}$ in a rather poor yield, due to difficulties in the Wacker oxidation step (Scheme 20). Alkylation of the kinetic enolate followed by deprotection of the hydroxy functionality rendered 40, again in somewhat unsatisfactory yield due to the alkylation step (Scheme 20). Remarkably, the high optical purity of the starting homoallylic alcohol 49a was preserved throughout the synthetic sequence.

$$
48 \underset{\substack{(86 \%,>95 \% \text { ee }) \\ \text { 49a }}}{\mathrm{Men}}
$$

i. $2 c$, (S)-TRIP $(5 \mathrm{~mol} \%)$, toluene, $-30^{\circ} \mathrm{C}, 3$ days; ii. TBSCl (1.1 equiv), imidazole (2 equiv), DMAP (10 mol\%), DMF, $60{ }^{\circ} \mathrm{C}, 3$ days; iii. $\mathrm{PdCl}_{2}(25 \mathrm{~mol} \%)$, CuCl $\left(1.5\right.$ equiv), DMF/ $\mathrm{H}_{2} \mathrm{O}$ (4:1), $40^{\circ} \mathrm{C}, 3$ days; iv. i $\mathrm{Pr}_{2} \mathrm{NH}$ (2.5 equiv), nBuLi (2.5 equiv), Etl ( 3.5 equiv), THF, -78 to $20^{\circ} \mathrm{C}, 3 \mathrm{~h}$; v. HF ( 16 equiv), TBAF ( 20 equiv), THF, $40^{\circ} \mathrm{C}, 3$ days

Scheme 20 Synthesis of $(5 R, 6 S)-(+)$-pteroenone 40

The most recent work in this field from Kotora involves the combination of the TRIP-catalyzed allylboration and olefin metathesis reactions, applied to the total synthesis of cobaicin D 41 (Scheme 18)..$^{40}$ Once again, the authors first confirmed the superiority of this catalytic enantioselective allylation methodology over the chiral $N$-oxide addition of allyltrichlorosilane. The authors then used this method to install the only stereocenter in the molecule starting from 6-heptenal $\mathbf{5 1}$ (accessible by simple oxidation of the corresponding alcohol) (Scheme 18). Esterification with acryloyl chloride 53, followed by ring-closing metathesis (RCM) catalyzed by Grubbs second 
generation catalyst (G-II), afforded lactone $\mathbf{5 4}$ along with its dimer dim-54 in 24 and 52\% yield respectively (Scheme 18). The formation of the dimer carries no drawbacks since it also proved competent as the starting material for the following crossmetathesis (CM) step with 55, which itself was previously synthesized via zirconocene-mediated coupling of TMS-propyne 56 and TMS-protected allylic alcohol 57 (Scheme 18). Grubbs second generation catalyst (G-II) was also used for the CM step, resulting in a moderate yield. The final step consists of an NCSmediated chlorodesilylation affording cobaicin D $\mathbf{4 1}$ as a 73:27 $E / Z$ mixture at the vinyl chloride moiety, in moderate yield (Scheme 18).

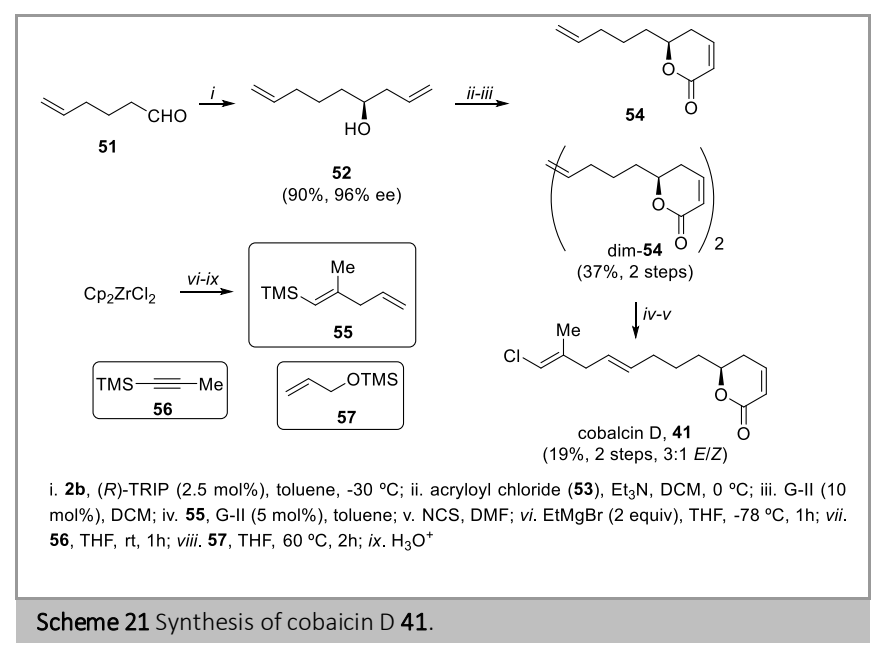

\section{Variants}

In January 2012, the groups of Reddy ${ }^{46}$ and Antilla ${ }^{47}$ independently reported the related propargylation of aldehydes with allenylboronate $\mathbf{2 p}$ catalyzed by chiral BINOL phosphoric acids. Homopropargylic alcohols (58) are useful groups in chemical synthesis, lending themselves to further transformations such as cross couplings and heterocycle synthesis (in fact, Antilla describes several further transformations with complete retention of ee). Previously, methods to synthesize enantiopure homopropargylic alcohols were scarce, and often had major limitations such as the need for stoichiometric chiral inductors, possible toxic by-products from metal catalysts or inconvenient propargylation reagents. ${ }^{48,49}$ These original reports overcame these limitations through the use of non-toxic organocatalysts and bench-stable allenylboronates as the propargylation agent. The two groups described different optimum conditions for the reaction, although both coincided that TRIP was the best catalyst in terms of enantioselectivity (Scheme 22). However, the conditions described by Reddy were more efficient, achieving similar or better results with $5 \mathrm{~mol} \%$ catalyst loading compared to the 20 mol\% used by Antilla, and in just a fraction of the reaction time.

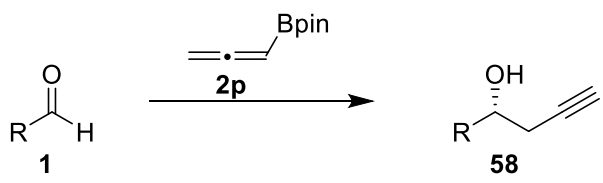

Conditions A (Antilla, ref 46):

(R)-TRIP (20 mol\%),

Toluene, $4 \AA$ M.S., $-20^{\circ} \mathrm{C}, 96 \mathrm{~h}$

Conditions $B$ (Reddy, ref 45$)$ :

(R)-TRIP (5 mol\%),

Cyclohexane, $5 \AA$ M.S. $10^{\circ} \mathrm{C}, 12 \mathrm{~h}$

13 examples

15 examples

$87-96 \%$ yield, $77-96 \%$ ee

$92-98 \%$ yield, $84->99 \%$ ee

Scheme 22 Comparison of the conditions used by Antilla and Reddy in the (R)TRIP-catalyzed propargylation of aldehydes.

In general, both groups reported slightly lower enantioselectivities when dealing with aliphatic aldehydes, although Reddy obtained slightly higher enantioselectivities for those substrates described in both papers; the difference is striking in the case of 2-phenylacetaldehyde, for which Reddy describes an ee of $>99 \%$ and Antilla $79 \%$. Cyclohexanecarboxaldehyde gave the lowest enantioselectivity, and this result was explained in 2013 by Goodman (see section 5 below). 50

The allylboration reaction catalyzed by chiral Brønsted acids has also seen other developments in recent years. In 2013 Malkov published a stereoselective synthesis of $Z$-homoallylic alcohols 60 via kinetic resolution of racemic secondary allylboronates 59 (Scheme 23 below). ${ }^{51}$ This work directly set out to tackle the problems reported when using secondary boron reagents: (1) earlier studies had described the ability of enantiopure secondary boronates to directly confer their stereochemistry to the product, although in practice these reactions often lead to synthetically inadequate mixtures of the $E / Z$ isomers depending on the $\alpha$-substituent; and (2) previously there were very few examples of obtaining both geometrically and enantiomerically pure Z-homoallylic alcohols. Following reports by Hoffmann and Weidmann, ${ }^{52}$ as well as Pietruszka and Schone (who described the favourable formation of the $Z$ isomer over the $E$ isomer with more sterically hindered boronates), 53 the authors started their investigation with the racemic pinacol boronate. Despite obtaining high enantioselectivities, their preliminary studies achieved a $Z: E$ ratio of just 80:20 when carrying out the reaction at $-78{ }^{\circ} \mathrm{C}$ in the presence of acetic acid as an additive, prompting an in silico analysis of the reaction mechanism (Figure 4).

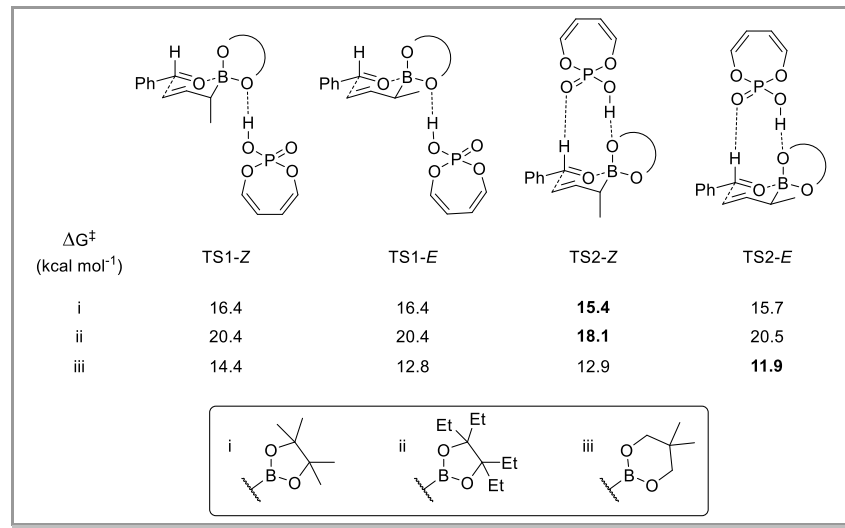

Figure 4 Relative stabilities of proposed transition states with varying size of the boronate ester. 
The authors found firstly that the two-point binding transition states (TS2) proposed by Goodman in $2012^{54}$ were energetically favourable over the single-point binding models (TS1) proposed by Antilla in his original report in 2010 (for a detailed discussion on the computational insights into this transformation, see Section 5 below), ${ }^{18}$ and secondly that TS2-Z was only $0.3 \mathrm{kcal} \mathrm{mol}$ ${ }^{1}$ more energetically favourable than TS2- $E$ when using a pinacol borate species. However, in accordance with the previously mentioned studies by Hoffmann and Pietruszka, when the steric bulk of the boronate group was increased from tetramethyl to tetraethyl the energy difference increased to $2.4 \mathrm{kcal} \mathrm{mol}^{-1}$, experimentally this would lead to a greater difference in reaction rate and therefore a more useful degree of $Z$ selectivity. The calculations also showed that the smaller 2,2-dimethylpropan1,3-diol boronate favoured the $E$ isomer by $1 \mathrm{kcal} \mathrm{mol}^{-1}$, as expected. The computationally predicted selectivity values were subsequently found to be in strong agreement with the experimentally observed values.

To conclude the study, the authors optimized the reaction conditions using tetraethylethylene glycol boronate derivatives 59 and obtained a variety of $Z$-homoallylic alcohols $\mathbf{6 0}$ in high yields and with an $E: Z$ ratio of $>25: 1$ in most cases (Scheme 23).

Scheme 23 Enantioselective synthesis of $Z$-homoallylic alcohols via kinetic
resolution of racemic secondary allylboronates
1
eq.

In recent years Murakami has been at the forefront of new developments in this field, publishing what would be the first of several related transformations in 2011, and the first enantioselective example catalyzed by chiral Brønsted acids in 2013.55-59 The group has developed a series of transition-metalcatalyzed alkene transpositions of alkenylboronates-forming the corresponding allylboronate in situ-in relay with the subsequent allylboration reaction of aldehydes (Scheme 24).

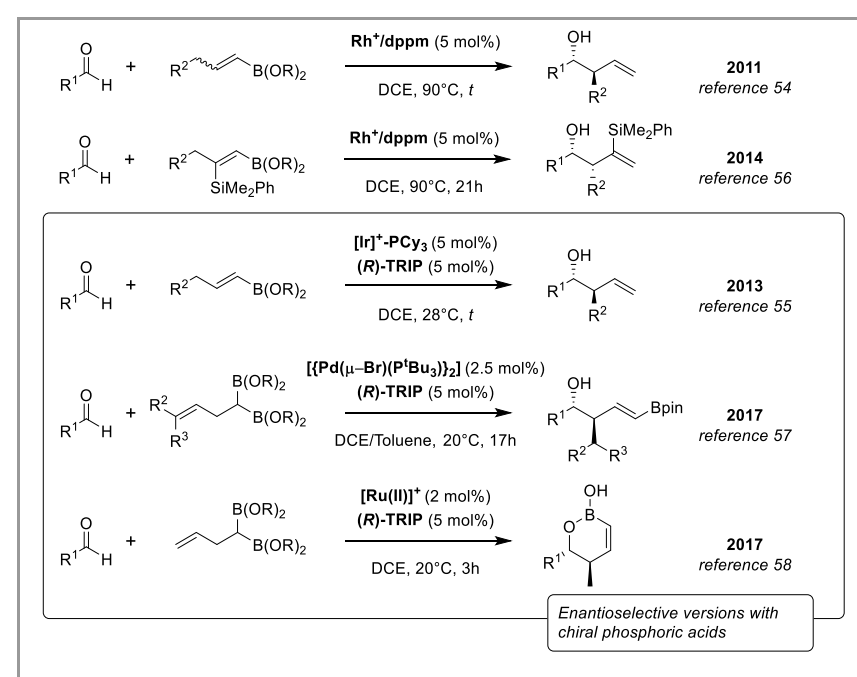

Scheme 24 Series of alkene isomerization/allylboration reactions developed by

\section{Murakami and co-workers.}

The work on this series of transformations began in 2011 when the Murakami group published the use of a rhodium catalyst to isomerize alkenylboronates $\mathbf{6 1}$ to allylboronates $\mathbf{2}$, which in the presence of benzaldehyde $\mathbf{1 a}$ readily formed the corresponding homoallylic alcohol 5. ${ }^{55}$ Alkenylboronates $\mathbf{6 1}$ are simpler substrates than their allylic counterparts $\mathbf{3}$, accessible via simple hydroboration of terminal alkynes 62 (see Scheme 26 below). Secondly, the geometry of the double bond in the starting material is unimportant in this transformation, whereas allylboronates need to be synthesized in a geometrically selective manner due to the stereospecific nature of the allylboration reaction. However, the process was imperfect and presented some drawbacks: the transposition was not completely selective towards (E)-crotylboronate 2c, leading to lowered diastereoselectivities in the one-pot process; and the process required heating at $90^{\circ} \mathrm{C}$.

In 2013 the group published the use of an iridium catalyst that possessed the activity they desired. After activation of iridium pre-catalyst 63 with hydrogen, the transposition took place at room temperature with much higher geometric selectivity (Table 2). ${ }^{56}$

Table 2 Comparison of iridium- and rhodium-based catalysts in the doublebond isomerization step

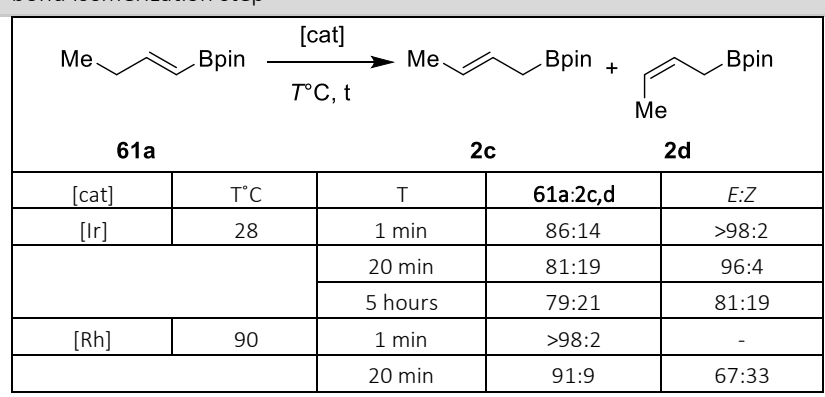

The lower temperatures accessible with the new iridium(I) catalyst (63) opened up the possibility of an enantioselective version of this transformation and, prompted by Antilla's report on Brønsted acid catalyzed allylborations in 2010,18 the group found that chiral phosphoric acid catalysts were compatible with the cationic iridium(I) species used in the alkene transposition. The authors carried out the reaction on a wide scope of substrates to afford a variety of anti-homoallylic alcohols $\mathbf{5}$ with different substituents on both the boronate and the aldehyde, showcasing the compatibility of the process with aliphatic, conjugated, electron-withdrawing, electron-donating and heteroaromatic aldehydes, as well as allylboronates bearing remote halogens, esters and silyl ethers. There were two noteworthy examples from this scope: (1) cyclohexanecarboxaldehyde gave a slightly lower enantioselectivity than other aldehyde derivatives (88\% ee), similar to results described in earlier reports; and (2) a silyl ether in the $\delta$ position (directly bonded to the double bond of the allylboronate formed after the transposition step) almost completely negated the chiral induction of the chiral phosphoric acid (17\% ee) (Scheme 25$)$. 


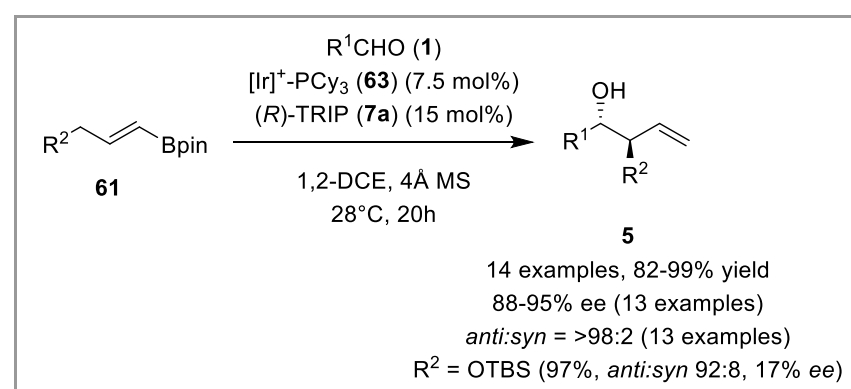

Scheme 25 Synthesis of homoallylic alcohols via iridium-catalyzed double bond isomerization followed by $(R)$-TRIP catalyzed allylboration.

Not only did Murakami describe the tandem iridium(I)-catalyzed transposition/Brønsted acid-catalyzed allylboration, but the alkenylboronates $\mathbf{6 1}$ used could be synthesized by hydroboration of terminal alkynes $\mathbf{6 2}$ with no purification step in between; the whole sequence could be executed in a one-pot fashion. Furthermore, the transposition was more $E$-selective, thereby giving excellent diastereoselectivities even when starting with the $E$-alkenylboronates $\mathbf{6 1}$ resulting from the hydroboration reaction (Scheme 26).

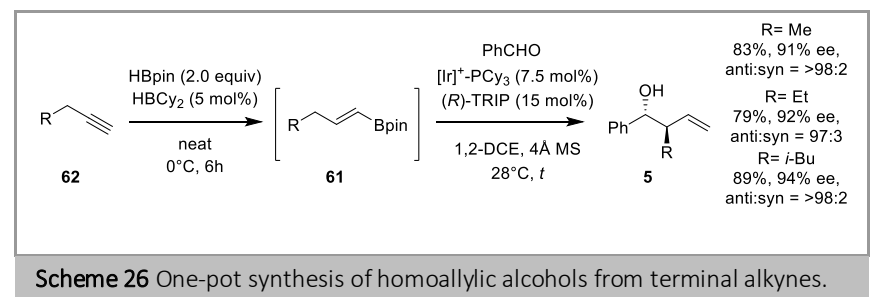

Also worthy of note is that the double bond of the boronate can seemingly be in any position of the alkyl chain and still result in the desired anti-homoallylic alcohol. Isomerization occurs via a chain-walking mechanism until the allylboronate is formed, which then immediately reacts with the aldehyde in the reaction mixture. Of course, this will also continuously shift the equilibrium to favour the formation of the reactive allylboronate until the starting boron species is consumed. The authors demonstrated this by carrying out the transformation with 3 - and 5-alkenylboronates $(\mathbf{6 4 a}, \mathbf{b})$, obtaining similar yields and enantioselectivities, albeit with longer reaction times (Scheme 27).

\begin{tabular}{|c|c|c|c|}
\hline & $\begin{array}{c}\mathrm{PhCHO} \\
{\left[\mathrm{Ir}^{+}-\mathrm{PCy}_{3}(7.5 \mathrm{~mol} \%)\right.} \\
(R)-\mathrm{TRIP}(15 \mathrm{~mol} \%)\end{array}$ & $\underline{\mathrm{O}} \mathrm{H}$ & $\begin{array}{c}\mathbf{5 d} \\
97 \%, 95 \% \text { ee } \\
\text { anti:syn }=>98: 2\end{array}$ \\
\hline $\begin{array}{l}64 a, n=0 \\
64 b, n=2\end{array}$ & $\begin{array}{c}1,2-\mathrm{DCE}, 4 \AA \mathrm{AS} \\
28^{\circ} \mathrm{C}, 2 \mathrm{~h}\end{array}$ & & $\begin{array}{c}\mathbf{5 e} \\
87 \%, 91 \% \text { ee } \\
\text { anti:syn }=>98: 2\end{array}$ \\
\hline
\end{tabular}

Scheme 27 Allylboration of benzaldehyde using allylboronates formed via a chain-walking-like mechanism with distant double bonds.

Carboni and co-workers published a similar paper the following year also making use of an iridium catalyst for the transposition step. ${ }^{60}$ These authors, however, took a different approach to the preparation of the alkenylboronate starting materials $\mathbf{6 1}$, synthesizing them by cross metathesis of terminal alkenes $\mathbf{6 5}$ with vinyl boronic pinacol ester $\mathbf{6 1 b}$ as reported in a previous paper of theirs (Scheme 25). ${ }^{61}$ The authors argue that this approach provides a complementary method to that published by Murakami the year before: given the higher reactivity of terminal alkynes $\mathbf{6 2}$ than alkenes $\mathbf{6 5}$, the alkene starting materials are more suitable when dealing with highly complex substrates. A preliminary optimization of the isomerization step prompted a switch from ruthenium to iridium-based catalyst which, although different to the complex used by Murakami, again needed preactivation with hydrogen gas to form the active species $\left[\mathrm{IrH}_{2}(\mathrm{THF})_{2}\left(\mathrm{PPh}_{2} \mathrm{Me}\right)_{2}\right] \mathrm{PF}_{6}(\mathbf{6 6})$. The group then began exploring an enantioselective version of the process. Of course, a chiral phosphoric acid was a good choice given the recent developments, hence a brief optimization using TRIP 7a. Unfortunately, the enantioselectivities were relatively low when compared to those seen in previous reports. Even so, the authors obtained a small range of enantioenriched products $\mathbf{5}$ with enantiomeric excesses of 54-82\% (Scheme 28). A disadvantage with this procedure was the need to change solvents after the isomerization step, which was carried out in THF, since the asymmetric allylboration reaction is generally more successful in less coordinating solvents such as toluene. It is likely that the authors could have developed a method rendering the change of solvent unnecessary. For example, Murakami achieved both the isomerization and allylboration in the same pot in dichloroethane, obtaining high yields and high enantioselectivities.

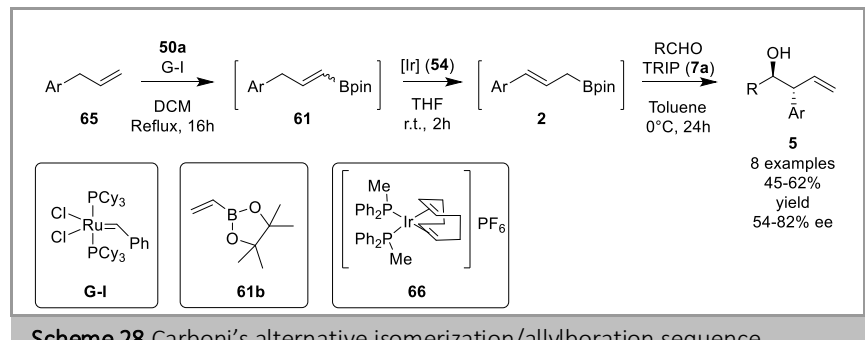

Scheme 28 Carboni's alternative isomerization/allylboration sequence

The same group used this strategy one year later in the synthesis of neolignans based on the trans-2-aryl-2,3-dihydrobenzofuran skeleton 67, an important class of secondary plant metabolites that show diverse biological activities. ${ }^{62}$ Specifically, the TRIPcatalyzed enantioselective version was used to prepare an intermediate in their synthesis of 3',4-di- $O$-methylcedrusin (68). Despite only obtaining a modest enantioselectivity of $24 \%$, the work represented a step forward in this area given the far greater complexity of the substrates used compared to the relative simplicity of past examples (Scheme 29). 


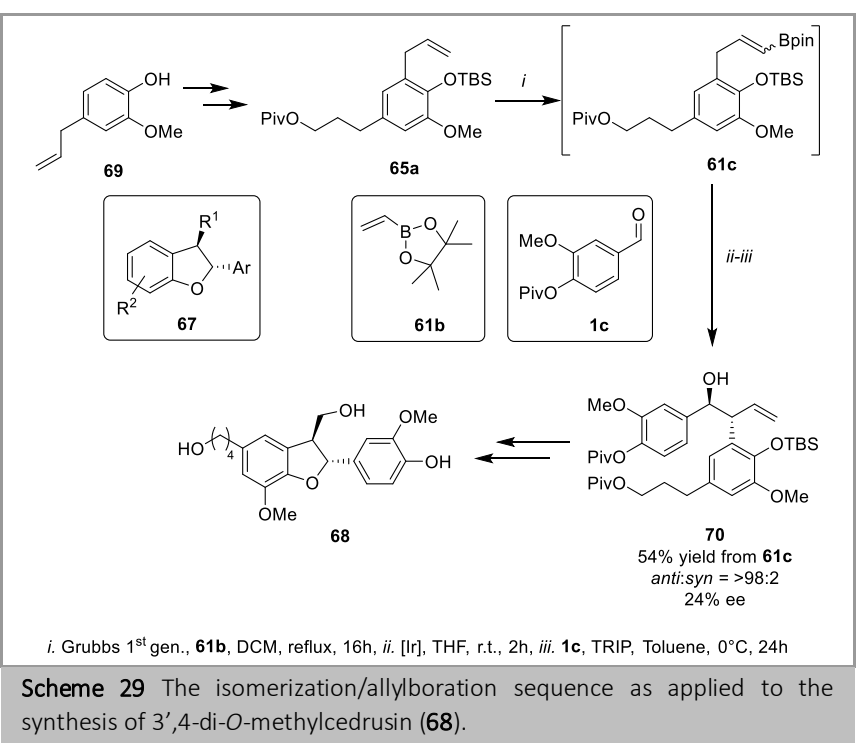

Four years later, in 2017, Murakami published two more papers relating to these tandem processes, focusing this time on the synthesis of $\delta$-boryl-substituted anti-homoallylic alcohols $\mathbf{7 1}$ (Schemes 30-33). ${ }^{58,59}$ The novelty of this work is that the starting materials bear not one but two boronic esters (or three in one case), leading to products that maintain a boryl functional group amenable to further transformations.

In this new venture, the authors first tested the conditions reported in 2013 (iridium(I) and TRIP) with the new starting substrate 1,1-di(boryl)but-3-ene 72a but, although the allylation reaction took place with the allylboronate resulting from the iridium-catalyzed transposition, the products formed were unsatisfactory mixtures of $E$ and $Z$ isomers, as well as unidentified by-products. The authors then looked into the use of other metals, and decided to test the reaction with the palladium(I) complex $\left[\left\{\mathrm{Pd}(\mu-\mathrm{Br})\left(\mathrm{P}^{+} \mathrm{Bu}_{3}\right)\right\}_{2}\right]$ (73), which was originally described by Gooßen and co-workers for double bond transposition. ${ }^{63}$ The reaction of $\mathbf{7 2 a}$ with benzaldehyde $\mathbf{1 a}$ in the presence of this palladium(I) complex $\mathbf{7 3}$ and $(R)$-TRIP 7a gave the corresponding $(E)$ - $\delta$-boryl-anti-homoallylic alcohol $\mathbf{7 1}$ in an $82 \%$ yield and excellent stereo- and enantioselectivity when stirred for $17 \mathrm{~h}$ at $20^{\circ} \mathrm{C}$ (Scheme 30 ).

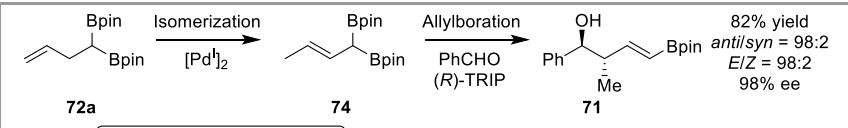

$$
\begin{aligned}
& {\left[\mathrm{Pd}^{\prime}\right]_{2}=>_{-\mathrm{Pd}_{-}-\mathrm{Br}_{73}^{-}-\mathrm{Br}^{-}-\mathrm{Pd}}<}
\end{aligned}
$$

Scheme 30 Preliminary results in the $\delta$-boryl-substituted anti-homoallylic alcohols 71 .

This outcome was not immediately obvious, since the anti:syn ratio was higher than the $E: Z$ ratio observed in the isolated transposition step in the absence of aldehyde (88:12). This observation prompted the authors to examine the relative reactivity of the $E$ and $Z$ isomers of the boron species, which they did by running a reaction starting with a 1:1 ratio of both allylboronates $\mathbf{7 4}$ (Scheme 31). They found that after 30 minutes the $E$ isomer had been completely consumed, whereas only $55 \%$ of the $Z$ isomer had been consumed; the $E$ isomer reacts faster than the $Z$ isomer, thereby giving rise to a higher anti:syn ratio than the $E: Z$ ratio of the allylboronate. Also worthy of note, is that the transition states proposed for this transformation suggest that the $Z$ stereoisomer $(Z)-\mathbf{7 1}$ should be the major product, contrary to what the authors observed. After examining the ratio of products at various reaction times they found that $(Z)-71$ was indeed the major product from the allylboration reaction, but the palladium catalyst $\mathbf{7 3}$ further isomerized this to the corresponding $(E)$ - $\delta$-boryl-anti-homoallylic alcohol $(E)$-71 after long reaction times. This second palladium(I)-catalyzed isomerization is what differentiates this report from the group's latest publication using ruthenium catalyst $\mathbf{7 5}$; with the latter this second isomerization does not occur, rendering the process $Z$-selective (Scheme 31).

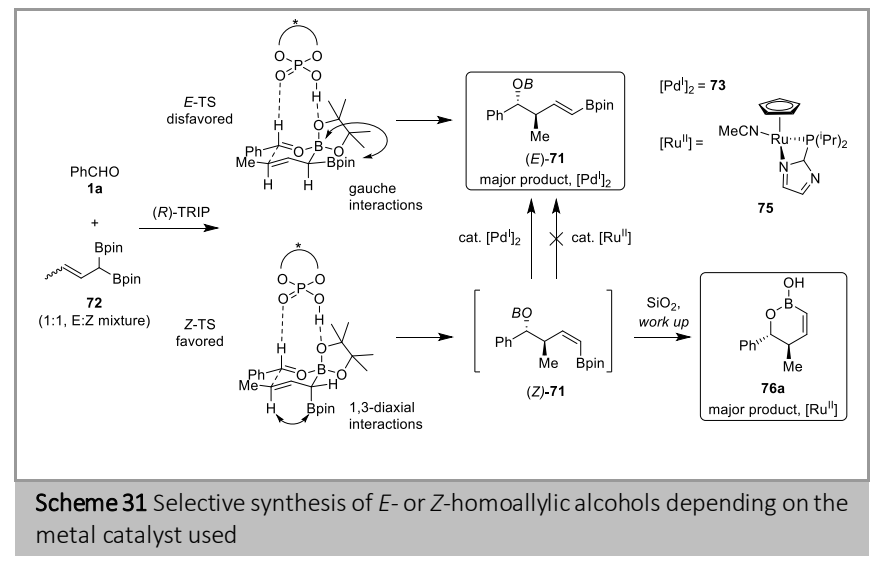

In terms of the scope of these reactions, the authors explored a variety of aliphatic, aromatic and heteroaromatic aldehydes, obtaining excellent enantio- and stereoselectivities (both $E / Z$ and anti/syn) in all cases with both catalysts (Scheme 32). They also explored the use of different boronates $\mathbf{7 2}$ yielding slightly different results. Interestingly, when 1,1-di(boryl)-4-phenylbut3-ene $\mathbf{7 2 b}$ was used, the first double bond isomerization did not take place with the ruthenium(II) catalyst 75 , even at $80^{\circ} \mathrm{C}$. This outcome was most likely due to the slightly lower reactivity of the ruthenium catalyst $\mathbf{7 5}$ when compared to palladium (73), coupled with the stabilizing effect of the phenyl ring on the double bond in that position. Another noteworthy example is the use of 1,1,4-tri(boryl)but-3-ene 72c; the reaction with this triboronate occurred selectively to give the 2(methylboronate)oxaborinan-3-ene derivative 77, despite having two reactive sites. 


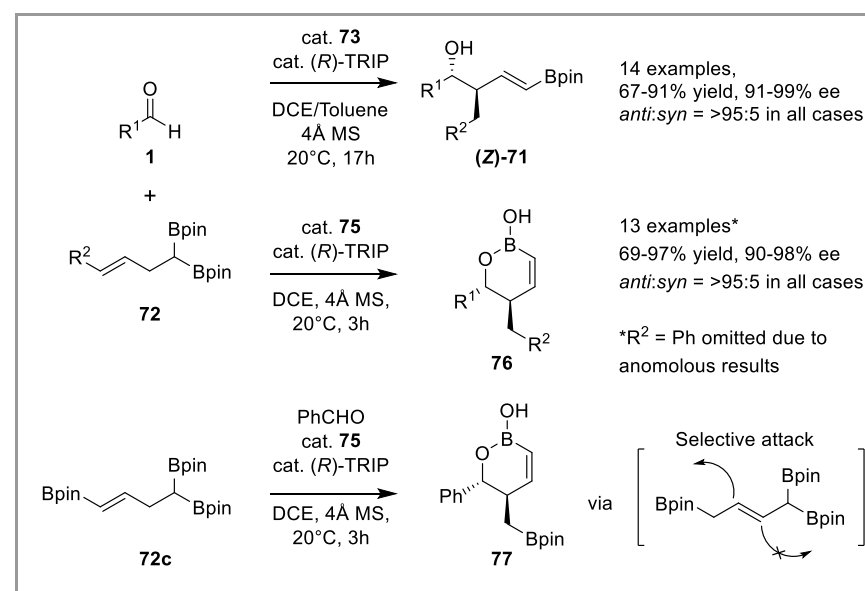

Scheme 32 Murakami's asymmetric isomerization/allylboration sequence used in the synthesis of diverse boronate-containing products.

The authors then explored the reactivity of these novel products, utilizing them successfully in a variety of transformations: palladium-catalyzed hydrogenations (78) and Suzuki-Miyaura couplings with aryl (79) and vinyl iodides (80); copper-catalyzed brominations (81) and intramolecular Chan-Lam couplings (82); esterification of the boron with a diene-bearing alcohol and subsequent intramolecular Diels-Alder reaction (83); and oxidation of the $\mathrm{C}-\mathrm{B}$ bond to give the 5-membered cyclic scaffold in the one-pot synthesis of (+)-trans-whisky lactone 84 (Scheme 33). Furthermore, using 2-(methylboronate)oxaborinan-3-ene $\mathbf{7 7}$ the authors were able to discriminate between the two $\mathrm{C}-\mathrm{B}$ bonds, successfully carrying out a Suzuki-Miyaura coupling with the $\mathrm{C}\left(\mathrm{sp}^{2}\right)-\mathrm{B}$ whilst leaving the $\mathrm{C}\left(\mathrm{sp}^{3}\right)-\mathrm{B}$ intact (85). Notably, all of these transformations took place with complete retention of the anti:syn ratio and optical purity.

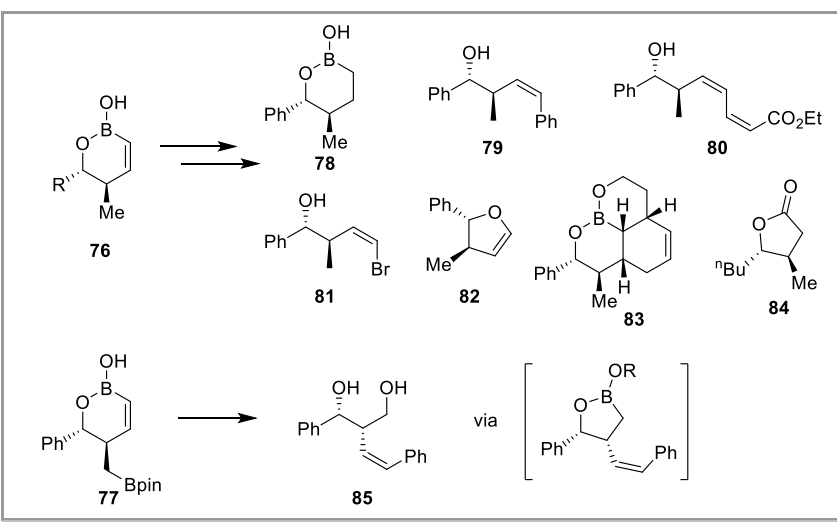

Scheme 33 Examples of the diverse chemistry of oxaborinan-3-ene compounds explored by Murakami and co-workers.

In recent years, Gong has also been active in the same area as Murakami: transition-metal catalyzed allylboronate formation followed by the sequential allylboration of aldehydes. ${ }^{64,65}$ In 2015 the group published their first example, in which they use a palladium catalyst to activate an allylic $\mathrm{C}-\mathrm{H}$ bond to form an allylboronate (2) which, in the presence of an aldehyde, then reacts to form the corresponding anti-homoallylic alcohol (5). ${ }^{64}$ The proposed reaction mechanism involves a phosphoric acid binding to the palladium center that the authors suspect is the species responsible for the $\mathrm{C}-\mathrm{H}$ activation; the phosphonate can abstract the allylic hydrogen to regenerate the phosphoric acid, leaving the allyl anion coordinated to the palladium (Scheme 34). Therefore, the authors reasoned that since previous reports had achieved high enantioselectivity with TRIP, using a chiral phosphoric acid in the process should also give high enantioselectivity. However, this was not the case, as only modest enantioselectivities were observed.

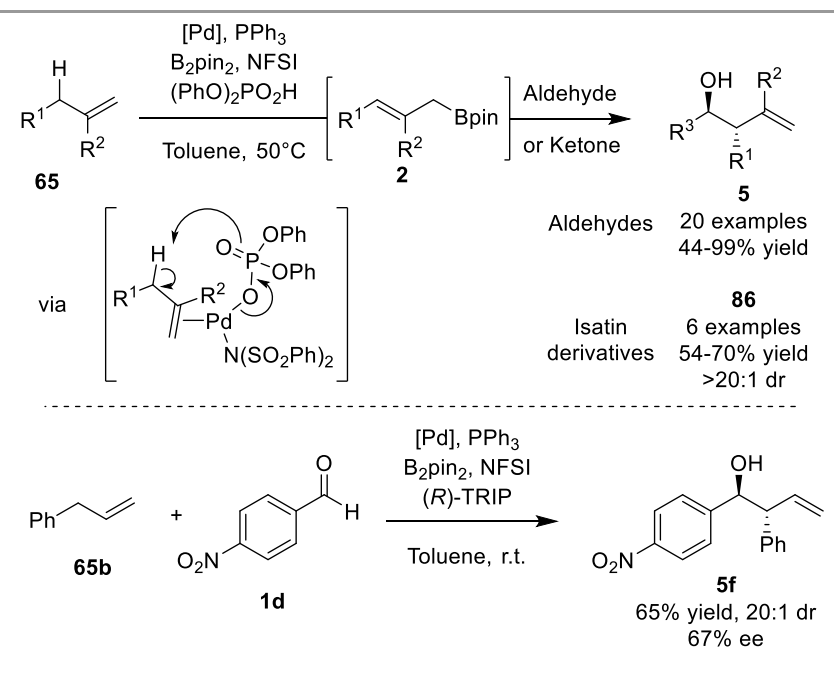

Scheme 34 a) Borylation/allylboration sequence developed by Gong and coworkers. b) An enantioselective example catalyzed by (R)-TRIP.

In 2017 the same group published another report focusing on the same reaction sequence, but using a double chiral induction strategy: the use of chiral boronates $\mathbf{8 7}$ as well as a chiral catalyst 7 (Scheme 35). ${ }^{65}$ This time the enantioselectivities were much higher, with many examples of products with over 90\% ee. Interestingly, unlike previous reports in which TRIP 7a has always provided the best enantioselectivity, the group reports the best results with the 9-anthryl BINOL phosphoric acid 7c. This may be due to the higher steric demand of the aryl substituent. Barrio and Akiyama reported a similar result when using a TMS-substituted allylboronate (see above, Scheme 17). ${ }^{34}$ Unfortunately, the palladium-catalyzed borylation had to be performed at higher temperatures, which hampered the enantioselectivity of the global process when all the reagents were present from the start. Therefore, the authors developed this chemistry as a sequential one-pot process-cooling the reaction before adding the aldehyde-resulting in much higher enantioselectivites. In terms of the aldehyde scope, the reaction was compatible with various aromatic aldehydes as well as cyclohexanecarboxaldehyde (Scheme 35). On the other hand, the boronate scope contains only aromatic substituents, of which all but two were very successful; there were problems when 3-(2phenylphenyl)prop-1-ene and $\alpha$-methylstyrene were used as the boronate precursors, likely due to steric hindrance. 


Scheme 35 Enantioselective synthesis of homoallylic alcohols through double
chiral induction in a borylation/allylboration sequence
antisyn $=20: 1$ (22 examples)

Not all the developments in this field have been regarding the actual reaction; in 2016 Pericàs described an operational advance in the asymmetric allylboration of aldehydes. ${ }^{66}$ The Pericás group has worked extensively with flow chemistry, ${ }^{67}$ and in 2016 they reported a process by which they were able to immobilize TRIP on a polystyrene-based resin. The authors state that the immobilization strategy was the most challenging part of this work, as only a few other examples of immobilizating chiral phosphoric acids had been reported; ${ }^{68,69}$ and the only one using TRIP had resulted in an inactive polymer. ${ }^{70}$ The group tackled this problem by using a co-polymerization strategy with styrene and divinylbenzene on a modified TRIP-scaffold (Scheme 36). Using this method, they were able to reliably produce a resin that contained $0.20-0.23$ mmol g-1 TRIP, which they determined through direct elemental analysis of phosphorus.

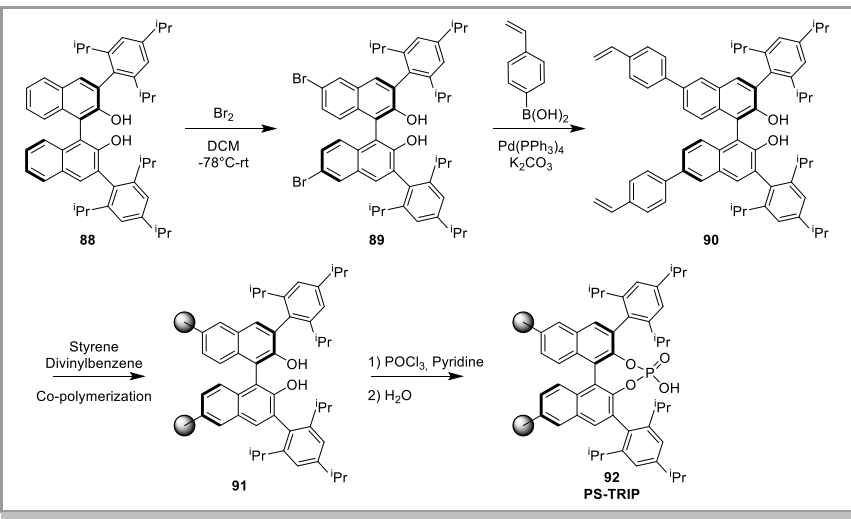

Scheme 36 Synthesis of polystyrene-supported (R)-TRIP

Remarkably, the authors were able to use the same resin to carry out the whole of the aldehyde scope-19 runs, including a final control run with benzaldehyde to confirm the complete retention of activity-obtaining good to excellent yields and enantioselectivities each time. A variety of aromatic aldehydes $\mathbf{1}$ were compatible with these reaction conditions, although slightly lower enantioselectivities were obtained in the case of 2-fluoroand 2-chlorobenzaldehyde (1e,f), as well as with octanal $(\mathbf{1 g})$ and, expectedly, 3-pyridine carboxaldehyde (1h). Several allylboronates 2 were also well tolerated (Scheme 37). An experiment in continuous flow was also run with no loss of activity or enantioselectivity, obtaining $4.60 \mathrm{~g}$ of the homo-allylic alcohol 5 product in an excellent $92 \%$ yield and $91 \%$ ee. In conclusion, this novel TRIP-functionalized resin 92 makes for a cost-efficient, recyclable and useful alternative to the traditional homogeneous version, and represents a step towards the future of synthetic organic chemistry.

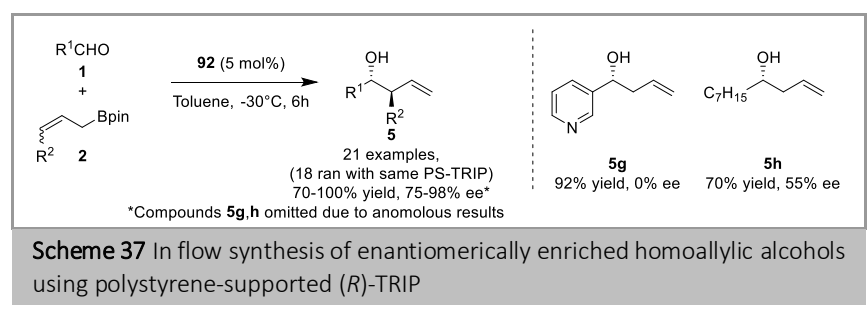

\section{Computational contribution}

In 2008, Sakata and Fujimoto reported a DFT (B3LYP/6-311G**) study which examined the mechanism of the Lewis acidcatalyzed allylboration of aldehydes. ${ }^{71}$ The reaction of allylboronic acid pinacol ester with benzaldehyde catalyzed by $\mathrm{AlCl}_{3}$ was selected for this study. Coordination of a monomeric $\mathrm{AlCl}_{3}$ molecule to the oxygens of the cyclic boronate and to the aldehyde oxygen were considered. It was concluded that the lowest energy pathway corresponded to that in which the aluminum species was coordinated to the pseudoequatorial oxygen of the boronate. This result supported the electrophilic boronate activation mode originally proposed by Rauniyar and Hall which was based on the findings of a series of experimental and kinetic studies. ${ }^{8 e}$ These experiments studied the addition of allylboronates to aldehydes catalyzed by $\mathrm{Sc}(\mathrm{OTf})_{3}$ and provided evidence that suggested a mechanism in which there is electrophilic boron activation by metal coordination to a boronate oxygen in a chair-like six-membered transition state.

DFT and QM/MM hybrid calculations reported by Goodman and co-workers in $2012^{54}$ explored the mechanism of Antilla's phosphoric acid-catalyzed asymmetric allylboration of aldehydes. ${ }^{18}$ These calculations showed that the preferred mechanism involved a six-membered ring chair-like transition structure (TS) in which there is a hydrogen-bonding interaction between the phosphoric acid's Brønsted acidic site and the pseudoaxial oxygen of the boron ligand (TS-1(major), Figure 5). A secondary catalyst-substrate interaction was also observed between the $\mathrm{P}=0$ oxygen and the aldehyde formyl proton. This formyl hydrogen-bonded pathway was found to be lower in energy than any of the activation modes containing just the catalyst-substrate $\mathrm{OH} \cdots \mathrm{O}$ hydrogen bond. An unfavorable steric clash between the pinacol ester methyl groups and the bulky catalyst aromatic group in the minor TS leads to the high levels of enantioselectivity observed experimentally (TS-1(minor), Figure 5). Cyclohexanecarboxaldehyde gave the lowest experimentally observed enantioselectivity (73\%). This was explained through further calculations and was found to be the result of the greater steric bulk of the cyclohexyl group which clashes with the aromatic group at the rear of the catalyst in the major transition state. However, in the minor transition state the aldehyde occupies an empty pocket, stabilizing this relative to the major transition state and thus lower levels of enantioselectivity are observed.

This DFT work also highlighted and led to the correction of the reported stereochemical outcome for two of the substrates reported by Antilla. 2-(Benzyloxy)acetaldehyde and thiophene2-carbaldehyde were reported to give their corresponding $(S)$ homoallylic alcohols in the presence of $(R)$-TRIP; suggesting a complete reversal in enantioselectivity relative to benzaldehyde. For 2-(benzyloxy)acetaldehyde, the optical rotation data was reviewed which showed the $(R)$-enantiomer had been formed 
instead. For thiophene-2-carbaldehyde, the optical data suggested the $(S)$-enantiomer had been formed. Subsequent calculations predicted the $(R)$-enantiomer should dominate. Therefore, the experiment was repeated with $(R)$-TRIP and the product confirmed as the $(R)$-homoallylic alcohol by Mosher ester analysis. This suggests that perhaps the opposite enantiomer of the catalyst was mistakenly used in Antilla's original allylboration of thiophene-2-carbaldehyde.

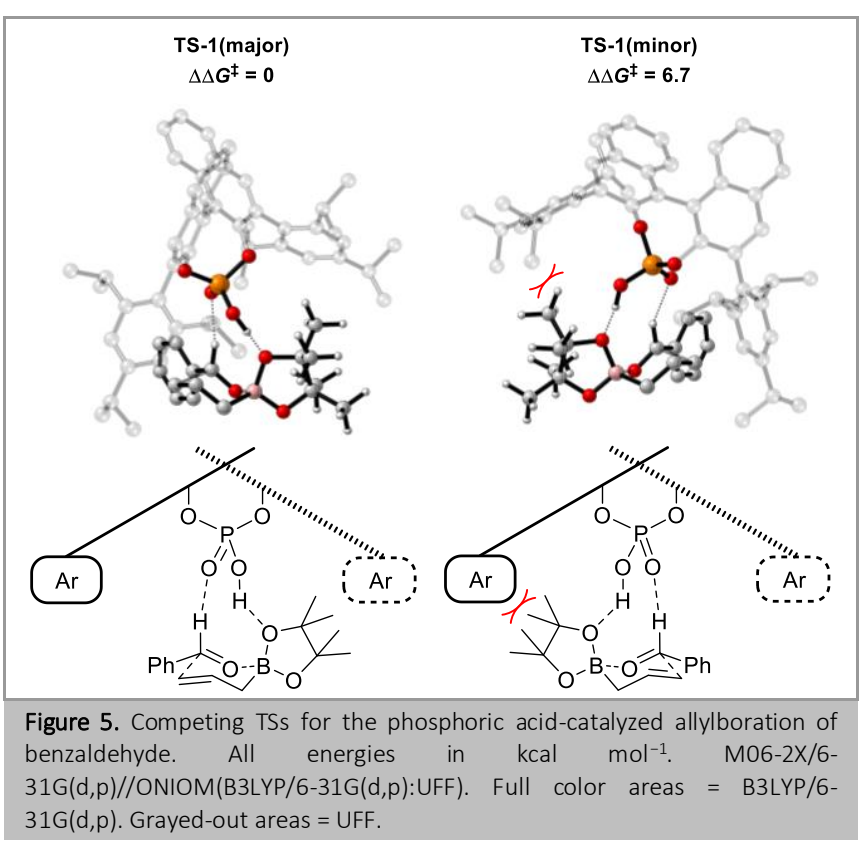

Goodman and co-workers also studied the mechanism ${ }^{50}$ of Antilla's phosphoric acid-catalyzed asymmetric propargylboration of aldehydes. ${ }^{47}$ With B3LYP, the lowest energy TS was calculated to be the formyl hydrogen-bonded pathway (TS-2(major), Figure 6) but the most favorable TS leading to the minor enantiomer involved protonation of the pseudoequatorial oxygen of the boron ligand and interaction of the $\mathrm{P}=\mathrm{O}$ oxygen with the ortho-hydrogen of the phenyl group of benzaldehyde (TS-3(minor), Figure 6). These observations are in agreement with DFT calculations reported by Houk and co-workers. ${ }^{47,72}$ However, whilst TS geometries calculated with B3LYP have been shown to be reliable, it is well-documented that the associated energies are inaccurate. ${ }^{73}$ Therefore, single-point energy calculations were performed with M06-2X on the B3LYP geometries. These results indicated that the lowest energy TSs leading to the major and minor products are those corresponding to the formyl hydrogen-bonded pathway (TS-2(major) and TS2(minor), Figure 6), and so the enantioselectivity can be rationalized using the same qualitative model and steric arguments described above for the allylboration reaction.

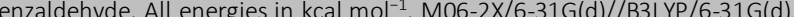
B3LYP/6-31G(d) free energies in parentheses.

Further computational studies have examined the asymmetric allyl(propargyl)boration of ortho-alkynyl benzaldehydes. ${ }^{31}$ The experimentally observed enantioselectivity was found to be highly dependent on the nature of the alkyne substituent. Low levels of enantioselectivity were observed for a terminal alkyne (62\% ee). Once again, the lowest energy TS was calculated to be the formyl hydrogen bonded pathway (TS-4(major), Figure 7) but the lowest energy TS leading to the minor enantiomer did not contain this $\mathrm{CH} \cdots \mathrm{O}$ interaction (TS-4(minor), Figure 7). There are two possible conformations of the aldehyde, conformation 1 and 2 , Figure 7. Conformation 1 is favored over 2 by approximately 1 $2 \mathrm{kcal} \mathrm{mol}^{-1}$, depending on the substrate, because it avoids the unfavorable interactions between the alkyne's electron density and the oxyge $\in$ n lone pairs seen in conformation 2. However, conformation 1 leads to a lengthening and weakening of the formyl hydrogen bond in the TSs due to the proximity of the $\mathrm{P}=0$ to the alkyne ( $\mathrm{CH} \cdots \mathrm{O}$ increases from 2.24 to $2.65 \AA$ ). Therefore, adopting either aldehyde conformation destabilizes all formyl hydrogen bonded TSs relative to TS-4(minor), which can adopt aldehyde conformation 1 and preserve the hydrogen bonds between catalyst and substrate, thus yielding low levels of enantioselectivity. However, the weakening of the formyl hydrogen bond when adopting aldehyde conformation 1 can be offset by additional favorable catalyst-substrate interactions ( $\mathrm{CH}-\pi$ and $\mathrm{CH} \cdots \mathrm{O}$ interactions labeled $\mathrm{a}$ and $\mathrm{b}$ respectively, TS5(major), Figure 7) in aryl-substituted substrates and hence high levels of enantioselectivity were observed (up to $99 \%$ ee).

The allylboration of benzaldehyde was also studied using quasiclassical direct molecular dynamics simulations. ${ }^{74}$ It was found that there is an enhancement of the catalyst-substrate $\mathrm{OH} \cdots \mathrm{O}$ hydrogen bond and the formyl hydrogen bond from reactant to TS. As the B-O bond forms between boronate and aldehyde, there is partial charge separation. The basicity of the boronate oxygen and acidity of the formyl proton are increased as a result of this charge separation and thus the formation of both hydrogen bonds is enhanced. In this study, the strength of the $\mathrm{OH}^{\circ} \cdot \mathrm{O}$ hydrogen bond and the formyl hydrogen bond were calculated to be 14.5 and $4.6 \mathrm{kcal} \mathrm{mol}^{-1}$, respectively.

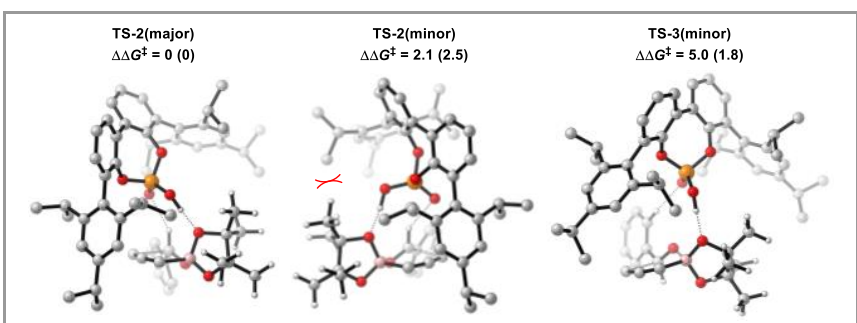

Figure 6 Competing TSs for the phosphoric acid-catalyzed propargylboration of 


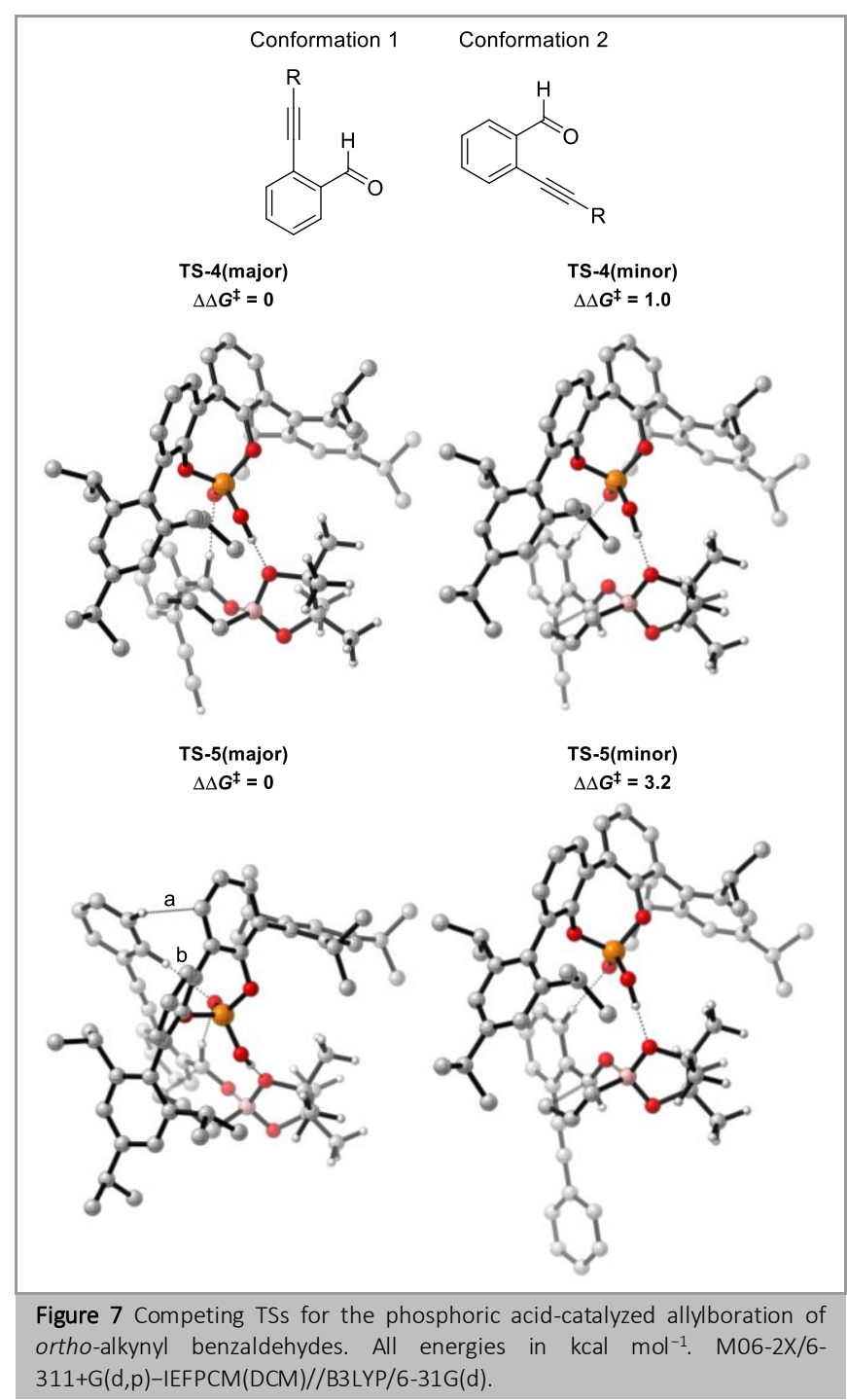

\section{Conclusions}

The asymmetric allylation of carbonyl compounds has played a central role in organic synthesis over the past forty years. Recently, the introduction of asymmetric Brønsted acid catalysis in this field has resulted in a major addition to the synthetic chemist's toolbox. As showcased in this review, this is a very active and creative area of research with contributions from many groups all around the world, and new developments may be anticipated for many years to come.

\section{Funding Information}

We thank the Spanish MINECO (CTQ2013-43310) and Generalitat Valenciana (PROMETEOII/2014/073) for their financial support. D. M. S is grateful to the Spanish Government for an FPU fellowship. We are grateful to Girton College, Cambridge (Research Fellowship to M.N.G.) for financial support.

\section{Acknowledgment}

\section{References}

(1) For recent reviews on asymmetric allylation reactions, see: (a) Yus, M.; González-Gómez, C.; Foubelo, F. Chem. Rev. 2013, 113, 5595. (b)
Yus, M.; González-Gómez, J. C.; Foubelo, F. Chem. Rev. 2011, 111, 7774.

(2) (a) Diner, C.; Szabó, K. J. J. Am. Chem. Soc. 2017,139, 2. (b) Huo, H.X.; Duvall, J. R.; Huang, M.-Y.; Hong, R. Org. Chem. Front. 2014, 1, 303. (c) Carreira, E. M.; Kvaerno, L. in: Classics in Strereoselective Synthesis Wiley-VCH, Weinheim, 2009, Chapter 5, p 164. (d) Lachance, H.; Hall, D. G. Org. React. 2008, 73, 1. (e) Denmark, S. E.; Fu, J. Chem. Rev. 2003, 103, 2763. (f) Denmark, S. E.; Almstead, N. G. in: Modern Carbonyl Chemistry; Otera, J., Ed; Wiley-VCH, Weinheim, 2000, 299. (g) Chemler, S. R.; Roush, W. R. in: Modern Carbonyl Chemistry; Otera, J., Ed.; Wiley-VCH, Weinheim, 2000, Chapter 10, 403. (h) Yamamoto, Y.; Asao, N. Chem. Rev. 1993, 93, 2207. (i) Roush, W. R. in: Comprehensive Organic Synthesis, Vol. 2; Trost, B. M., Ed.; Pergamon Press, Oxford, 1991, p 1.

(3) (a) Brown, H. C.; Jadhav, P. K. J. Am. Chem. Soc. 1983, 105, 2092. (b) Brown, H. C.; Bhat, K. S. J. Am. Chem. Soc. 1986, 108, 293. (c) Roush, W. R.; Walts, A. E.; Hoong, L. K. J. Am. Chem. Soc. 1985, 107, 8186. (d) Roush, W. R.; Ando, K.; Powers, D. B.; Palkowitz, A. D.; Halterman, R. L. J. Am. Chem. Soc. 1990, 112, 6339.

(4) Brown, H. C.; Racherla, U. S.; Pellechia, P. J. J. Org. Chem. 1990, 55, 1868.

(5) Denmark, S. E.; Weber, E. J. Helv. Chim. Acta 1983, 66, 1655.

(6) For a recent account on chair-like six-membered transition states, see: Mejuch, T.; Gilboa, N.; Gayon, E.; Wang, H.; Houk, K. N.; Marek, I. Acc. Chem. Res. 2013, 46, 1659.

(7) For some enantioselective allylations using other allylating reagents, see: (a) Furuta, K.; Mouri, M.; Yamamoto, H. Synlett 1991, 561. (b) Costa, A. L.; Piazza, M. G.; Tagliavini, E.; Trombini, C.; Umani-Ronchi, A. J. Am. Chem. Soc. 1993, 115, 7001. (c) Keck, G. E; Tarbet, K. H.; Geraci, L. S. J. Am. Chem. Soc. 1993, 115, 8467. (d) Denmark, S. E.; Fu, J. J. Am. Chem. Soc. 2001, 123, 9488. (e) Malkov, A.; Orsini, M.; Pernazza, D.; Muir, K. W.; Langer, V.; Meghani, P.; Kocovsky, P. Org. Lett. 2002, 4, 1047. (f) Kim, I. S.; Ngai, M.; Krische, M. J. J. Am. Chem. Soc. 2008, 130, 14891.

(8) (a) Kennedy, J. W. J.; Hall, D. G. J. Am. Chem. Soc. 2002, 124, 11586. (b) Ishiyama, T.; Ahiko, T.; Miyaura, N. J. Am. Chem. Soc. 2002, 124, 12414. (c) Lachance, H.; Lu, X.; Gravel, M.; Hall, D. G. J. Am. Chem. Soc. 2003, 125, 10160. (d) Wada, R.; Oisaki, K.; Kanai, M.; Shibasaki, M. J. Am. Chem. Soc. 2004, 126, 8910. (e) Rauniyar, V.; Hall, D. G. J. Am. Chem. Soc. 2004, 126, 4518.

(9) Yu, S. H.; Ferguson, M. J.; McDonald, R.; Hall, D. G. J. Am. Chem. Soc. 2005, 127, 12808.

(10) Rauniyar, V.; Hall, D. G. Angew. Chem. Int. Ed. 2006, 45, 2426.

(11) (a) Yamamoto, H.; Futatsugi, K. Angew. Chem. Int. Ed. 2005, 44, 1924. (b) Ishihara, K.; Kaneeda, M.; Yamamoto, H. J. Am. Chem. Soc. 1994, 116, 11179. (c) Nakamura, S.; Kaneeda, M.; Ishihara, K.; Yamamoto, H. J. Am. Chem. Soc. 2000, 122, 8120. (d) Ishihara, K.; Nakamura, S.; Kaneeda, M.; Yamamoto, H. J. Am. Chem. Soc. 1996, 118, 12854. (e) Ishihara, K.; Nakamura, S.; Yamamoto, H. J. Org. Chem. 1998, 63, 6444. (f) Ishihara, K.; Nakashima, D.; Hiraiwa, Y.; Yamamoto, H. J. Am. Chem. Soc. 2003, 125, 24.

(12) Paterson, I. Pure Appl. Chem. 1992, 64, 1821.

(13) (a) Rauniyar, V.; Hall, D. G. Synthesis 2007, 21, 3421. (b) Rauniyar, V.; Zhai, H.; Hall, D. G. J. Am. Chem. Soc. 2008, 130, 8481. (c) Rauniyar, V.; Hall, D. G. J. Org. Chem. 2009, 74, 4236. (d) Penner, M.; Rauniyar, V.; Kaspar, L. T.; Hall, D.G. J. Am. Chem. Soc. 2009, 131, 14216.

(14) (a) Lou, S.; Moquist, P. N.; Schaus S. E. J. Am. Chem. Soc. 2006, 128 12660. (b) Barnett, D. S.; Moquist, P. N.; Schaus S. E. Angew. Chem. Int. Ed. 2009, 48, 8679. (c) for a subsequent application to methallylation, see; Zhang, Y.; Li, N.; Qu, B.; Ma, S.; Lee, H.; Gonnella, N. C.; Gao, J.; Li, W.; Tan, Z.; Reeves, J. T.; Wang, J.; Lorenz, J. C.; Li, G.; Reeves, D. C.; Premasiri, A.; Grinberg, N.; Haddad, N.; Lu, B.Z.; Song, J. J.; Senanayake, C. H. Org. Lett. 2013, 15, 1710.

(15) Paton, R. S.; Goodman, J. M.; Pellegrinet, S. C. Org. Lett. 2009, $11,37$.

(16) For seminal contributions on chiral phosphoric acid catalysis, see: (a) Akiyama, T.; Itoh, J.; Yokota, K.; Fuchibe, K. Angew. Chem. Int. Ed. 2004, 43, 1566; (b) Uraguchi, D.; Terada, M.J.Am. Chem. Soc. 2004, $126,5356$. 
(17) For reviews on chiral phosphoric acid catalysis, see: (a) Merad, J.; Lalli, C.; Bernadat, G.; Maury, J.; Masson, G. Chem. Eur. J. 2018. DOI: 10.1002/chem.201703556 (b) Parmar, D.; Sugiono, E.; Raja, S.; Rueping, M. Chem. Rev. 2017, 117, 10608 (c) Parmar, D.; Sugiono, E.; Raja, S.; Rueping, M. Chem. Rev. 2014, 114, 9047 (d)Terada, M. Curr. Org. Chem. 2011, 15, 2227. (e) Terada, M. Bull. Chem. Soc. Jpn. 2010, 83, 101. (f) Terada, M. Synthesis 2010, 1929. (g) Zamfir, A.; Schenker, S.; Freund, M.; Tsogoeva, S. B. Org. Biomol. Chem. 2010, 8, 5262. (h) Terada, M. Chem. Commun. 2008, 4097. (i) Adair, G.; Mukherjee, S.; List, B. Aldrichimica Acta 2008, 41, 31. (j) Akiyama, T. Chem. Rev. 2007, 107, 5744. (k) Doyle, A. G.; Jacobsen, E. N. Chem. Rev. 2007, 107, 5173. (1) Akiyama, T.; Itoh, J.; Fuchibe, K. Adv. Synth. Catal. 2006, 348, 999. (m) Connon, S. J. Angew. Chem. Int. Ed. 2006, 45, 3909.

(18) Jain, P.; Antilla, J. C. J. Am. Chem. Soc. 2010, 132, 11884.

(19) In the SI of reference $13 \mathrm{~b}$ Hall described an unsuccessful attempt of using unsubstituted binolphosphoric acid as catalyst in an asymmetric allylation. Akiyama and Terada reported substitution at the $3,3^{\prime}$ positions of the BINOL skeleton as the key for achieving high enantioselectivities.

(20) Xing, C.-H.; Liao, Y.-X.; Zhang, Y.; Sabarova, D.; Bassous, M.; Hu, Q.S. Eur. J. Org. Chem., 2012, 1115.

(21) For recent applications of SPINOL-based phosphoric acids in asymmetric organocatalysis, see: (a) Glavac, D.; Zheng, C.; Dokli, I.; You, S.-L.; Gredicak, M. J. Org. Chem. 2017, 82, 8752. (b) Pinxterhuis, E. B.; Gualtierotti, J.-B.; Heeres, H. J.; de Vries, J. G.; Feringa, Ben L. Chem. Sci. 2017, 8, 6409. (c) Tay, J.-H.; Arguelles, A. J.; DeMars, M. D.; Zimmerman, P. M.; Sherman, D. H.; Nagorny, P. J. Am. Chem. Soc. 2017, 139, 8570.

(22) Allais, F.; Ducrot, P.-H. Synthesis 2010, 1649.

(23) (a) Álvarez-Bercedo, P.; Falomir, E.; Murga, J.; Carda, M.; Marco, J. A. Eur. J. Org. Chem. 2008, 4015. (b) Dittoo, A.; Bellosta, V.; Cossy, J. Synlett 2008, 2459.

(24) Ouedraogo, M.; Carreyre, H.; Vandebrouck, C.; Bescond, J.; Raymond, G.; Guissou, I.-P.; Cognard, C.; Becq, F.; Potreau, D.; Cousson, A.; Marrot, J.; Coustard, J.-M. J. Nat. Prod. 2007, 70, 2006.

(25) Evans, P. A.; Cui, J.; Gharpure, S. J. Org. Lett. 2003, 5, 3883.

(26) Bhakta, U.; Sullivan, E.; Hall, D. G. Tetrahedron 2014, 70, 678.

(27) Fustero, S.; Rodríguez, E.; Lázaro, R.; Herrera, L.; Catalán, S.; Barrio, P. Adv. Synth. Catal. 2013, 355, 1058.

(28) For a related transformation using the corresponding Ellman's imines, see: Fustero, S.; Lázaro, R.; Herrera, L.; Rodríguez, E.; Mateu, N.; Barrio, P. Org. Lett. 2013, 15, 3770.

(29) For selected examples of relay catalysis using chiral phosphoric acid/transition metal binary systems, see: (a) Zhu, Y.; He, W.; Wang, W.; Pitsch, C. E.; Wang, X.; Wang, X. Angew. Chem. Int. Ed. 2017, 56, 12206. (b) SachinNarute, RegevParnes, F. DeanToste, DoronPappo J. Am. Chem. Soc. 2016, 138, 16553. (c) Han, Z.-Y.; Chen, D.-F.; Y.-Y. Wang, R. Guo, P.-S. Wang, C. Wang, L.-Z. Gong, J. Am. Chem. Soc. 2012, 134, 6532; (d) M. Terada, Y. Toda, Angew. Chem. 2012, 124, 2135; Angew. Chem. Int. Ed. 2012, 51, 2093; (e) M. E. Muratore, C. A. Holloway, A.W. Pilling, R. I. Storer, G. Trevitt, D. J. Dixon, J. Am. Chem. Soc. 2009, 131, 10796; (f) Z.-Y. Han, H. Xiao, X.-H. Chen, L.-Z. Gong, J. Am. Chem. Soc. 2009, 131, 9182; (g) K. Sorimachi, M. Terada, J. Am. Chem. Soc. 2008, 130, 14452.

(30) For a cross-metathesis/intramolecular aza-Michael process, see: (a) Cai, Q.; Zheng, C.; You, S.-L. Angew. Chem. Int. Ed. 2010, 49, 8666. For a cross-metathesis/intramolecular Friedel-Crafts alkylation sequence, see: b) Cai, Q.; Zhao, Z. A.; You, S.-L. Angew. Chem. Int. Ed. 2009, 48, 7428.

(31) Rodríguez, E.; Grayson, M. N.; Asensio, A.; Barrio, P.; Houk, K. N.; Fustero, S. ACS Catal. 2016, 6, 2506.

(32) The same authors have showcased the utility of other orthosubstituted benzaldehyde derivatives in DOS, see: a) Herrera, L. ; Barrio, P.; Ibanez, I.; Roman, R.; Mateu, N.; Fustero, S. Org. Lett. 2016, 18, 4722; (b) Sedgwick, D. M.; Barrio, P.; Simon, A.; Román, R.; Fustero, S. J. Org. Chem. 2016, 81, 8876. (c) Lázaro, R.; Román, R.; Sedgwick, D. M.; Haufe, G.; Barrio, P.; Fustero, S. Org. Lett. 2016, 18, 948. (d) Barrio, P.; Ibañez, I.; Herrera, L.; Román, R.; Catalán, S.;
Fustero, S. Chem. Eur. J. 2015, 21, 11579 (e) Fustero, S.; Lázaro, R.; Aiguabella, N.; Riera, A.; Simón-Fuentes, A.; Barrio, P. Org. Lett. 2014, 16, 1224.

(33) Low ee's on several $o$-alkynylbenzaldehydes had already been reported by Kotora, see: Hessler, F.; Betík, R.; Kadlčíková, A.; Belle, R.; Kotora, M. Eur. J. Org. Chem. 2014, 7245.

(34) Barrio, P.; Rodriguez, E.; Saito, K.; Fustero, S.; Akiyama, T. Chem. Comm. 2015, 51, 5246.

(35) For a recent account on Barrio's contributions to the field, see: Barrio, P.; Rodríguez, E.; Fustero, S. Chem. Rec. 2016, 16, 2046.

(36) (a) Sawicki, M.; Kwok, A.; Tredwell M.; Gouverneur, V.; Beilstein J. Org. Chem. 2007, 3, 34. (b) Tredwell, M.; Tenza, K.; Pacheco, M. C.; Gouverneur, V. Org. Lett. 2005, 7, 4495. (c) Greedy, B.; Paris, J.-M.; Vidal, T.; Gouverneur, V. Angew. Chem., Int. Ed., 2003, 42, 3291. (d) Thibaudeau, S.; Gouverneur, V. Org. Lett. 2003, 5, 4891.

(37) Recently, the reverse reaction sequence (electrophilic allylic fluorination/allylboration) using isomeric $\gamma$-silylvinylboronates has been described: Mace, A.; Tripoteau, F.; Zhao, Q.; Gayon, E.; Vrancken, E.; Campagne, J.-M.; Carboni, B. Org. Lett. 2013, 15, 906.

(38) Hessler, F.; Korotvička, A.; Nečas, D.; Valterová, I; Kotora, M. Eur. J. Org. Chem. 2014, 2543.

(39) Koukal, P.; Kotora, M. Chem. Eur. J. 2015, 21, 7408.

(40) Kolská, K.; Ghavre, M.; Pour, M.; Hybelbauerová, S.; Kotora, M. Asian J. Org. Chem. 2016, 5, 646.

(41) (a) Bulej, P.; Kuchař, M.; Panajotova, V.; Jegorov, V. Collect. Czech. Chem. Commun. 1988, 53, 1862. (b) Grimová, J.; Vortel, V.; Lapka, R.; Lastovička, J. Cesk. Fyziol. 1988, 37, 249. (c) Grimová, J.; Vortel, V.; Lapka, R.; Lastovička, J. Cesk. Fyziol. 1990, 39, 133.

(42) For some selected examples, see: (a) Vlašaná, K.; Hrdina, R.; Valterová, I.; Kotora, M. Eur. J. Org. Chem. 2010, 7040. (b) Malkov, A. V.; Kysilka, O; Edgar, M.; Kadlčíková, A.; Kotora, M.; Kočovský, P. Chem. Eur. J. 2011, 17, 7162. (c) Motloch, P.; Valterová, I.; Kotora, M. Adv. Synth. Catal. 2014, 356, 199.

(43) Hellstrom, W. J. G. Neuropsychiatr. Dis. Treat. 2009, 5, 37.

(44) Lee, S. H.; Kim, I. S.; Li, Q. R.; Dong, G. R.; Jeong, L. S.; Jung, Y. H. J. Org. Chem. 2011, 76, 10011.

(45) Yoshida, W. Y.; Bryan, P. J.; Baker, B. J.; McClintock, J. B. J. Org. Chem. 1995, 60, 780 .

(46) Reddy, L.R. Org. Lett. 2012, 14, 2010.

(47) Jain, P.; Wang, H.; Houk, K. N.; Antilla, J. C. Angew. Chem. Int. Ed. 2012, 51, 1391.

(48) Ding, C. H.; Hou, X. L. Chem. Rev. 2011, 111, 1914.

(49) Usanov, D. L.; Yamamoto, H. Angew. Chem. Int. Ed. 2010, 49, 8169.

(50) Grayson, M. N.; Goodman, J. M. J. Am. Chem. Soc. 2013, 135, 6142.

(51) Pradillos, C. A. I.; Kabeshov, M. A.; Malkov, A. V. Angew. Chem. Int. Ed. 2013, 52, 5338.

(52) Hoffmann, R. W.; Weidmann, J. Organomet. Chem. 1980, 195, 137.

(53) Pietruszka, J.; Schöne, N. Eur. J. Org. Chem. 2004, 5011.

(54) Grayson, M. N.; Pellegrinet, S. C.; Goodman, J. M. J. Am. Chem. Soc. 2012, 134, 2716.

(55) Shimizu, H.; Igarashi, T.; Miura, T.; Murakami, M. Angew. Chem. Int Ed. 2011, 50, 11465.

(56) Miura, T.; Nishida, Y.; Morimoto, M.; Murakami, M. J. Am. Chem. Soc 2013, 135, 11497.

(57) Miura, T.; Nishida, Y.; Murakami, M. J. Am. Chem. Soc. 2014, 136, 6223.

(58) Miura, T.; Nakahashi, J.; Murakami, M. Angew. Chem. Int. Ed. 2017, $56,6989$.

(59) Miura, T.; Nakahashi, J.; Zhou, W.; Shiratori, Y.; Stewart, S. G.; Murakami, M. J. Am. Chem. Soc. 2017,139, 10903.

(60) Hemelaere, R.; Carreaux, F.; Carboni, B. Chem.-Eur. J. 2014, 20, 14518.

(61) Hemelaere, R.; Carreaux, F.; Carboni, B. J. Org. Chem. 2013, 78, 6786.

(62) Hemelaere, R.; Carreaux, F.; Carboni, B. Eur. J. Org. Chem. 2015, 2470 .

(63) (a) Ohlmann, D. M.; Tschauder, N.; Stockis, J.; Dierker, M.; Gooßen, L. J. J. Am. Chem. Soc. 2012, 134, 13716. (b) Mamone, P.; Grünberg, M. F.; Fromm, A.; Khan, B. A.; Gooßen, L. J. Org. Lett. 2012, 14, 3716. 
(64) Tao, Z.; Li, X.; Han, Z.; Gong, L. J. Am. Chem. Soc. 2015, 137, 4054.

(65) Li, L.; Tao, Z.; Han, Z.; Gong, L. Org. Lett. 2017, 19, 102.

(66) Clot-Almenara, L.; Rodríguez-Escrich, C.; Osorio-Planes, L.; Pericàs, M. A. ACS Catal. 2016, 6, 7647.

(67) (a) Martín-Rapún, R.; Sayalero, S.; Pericàs, M. A. Green Chem. 2013, 15, 3295. (b) Maestre, L.; Ozkal, E.; Ayats, C.; Beltran, A.; DiazRequejo, M. M.; Perez, P. J.; Pericás, M. A. Chem. Sci. 2015, 6, 1510. (c) Llanes, P.; Sayalero, S.; Rodríguez-Escrich, C. Green Chem. 2016, 18, 8. (d) Canellas, S.; Ayats, C.; Henseler, A. H.; Pericàs, M. A. ACS Catal. 2017, 7, 1383.

(68) Kundu, D. S.; Schmidt, J.; Bleschke, C.; Thomas, A.; Blechert, S. Angew. Chem. Int. Ed. 2012, 51, 5456.
(69) Rueping, M.; Sugiono, E.; Steck, A.; Theissmann, T. Adv. Synth. Catal. 2010, 352, 281.

(70) Mayer-Gall, T.; Lee, J. W.; Opwis, K.; List, B.; Gutmann, J. S. ChemCatChem 2016, 8, 1428 .

(71) Sakata, K.; Fujimoto, H. J. Am. Chem. Soc. 2008, 130, 12519.

(72) Wang, H.; Jain, P.; Antilla, J. C.; Houk, K. N. J. Org. Chem. 2013, 78, 1208.

(73) Simón, L.; Goodman, J. M. Org. Biomol. Chem. 2011, 9, 689.

(74) Grayson, M. N.; Yang, Z.; Houk, K. N. J. Am. Chem. Soc. 2017, 139, 7717.

\section{Biosketches}

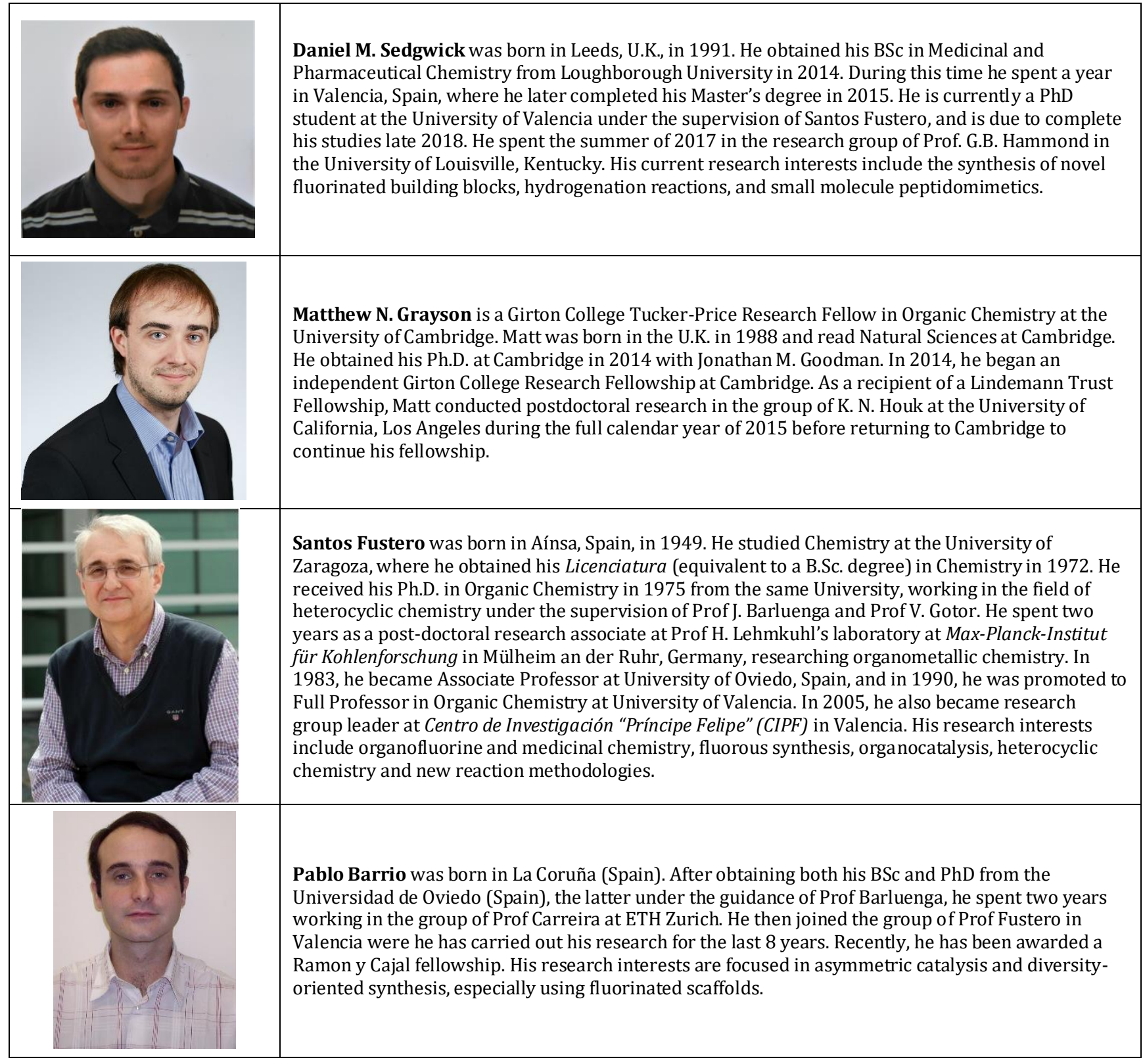

For Reviews, include photos and short biographical text for all authors. If the photo is of a group of people, specify who is shown where.

For Short Reviews, restrict the photo and biographical text to the main (starred) author(s). If the photo displays coworkers, however, they can be mentioned briefly within the main author's short biography. 
Photographs (.jpg or .tif format) must be a minimum of $300 \mathrm{dpi}$ in order to reproduce well in print.

\section{Checklist (have these on hand for manuscript submission in ScholarOne):}

- cover letter, including a statement of the work's significance

- full mailing address, telephone and fax numbers, and e-mail address of the corresponding author

- email address for each author

- original Word file

- original graphics files zipped into one zip file

- eye-catching graphical abstract as an individual file

- 5-8 key words

\section{Useful links:}

- SYNTHESIS homepage

- SYNTHESIS information and tools for authors

- Graphical abstract samples (PDF file download)

- What is "Primary Data"?

- ScholarOne (manuscript submission) 